\title{
BABA-Primed Histone Modifications in Potato for Intergenerational Resistance to Phytophthora infestans
}

\author{
Barbara Meller ${ }^{1}$, Daniel Kuźnicki ${ }^{1}$, Magdalena Arasimowicz-Jelonek ${ }^{2}$, Joanna Deckert ${ }^{2}$ \\ and Jolanta Floryszak-Wieczorek ${ }^{1 *}$ \\ ${ }^{1}$ Department of Plant Physiology, Poznań University of Life Sciences, Poznań, Poland, ${ }^{2}$ Department of Plant Ecophysiology, \\ Faculty of Biology, Adam Mickiewicz University in Poznań, Poznań, Poland
}

\section{OPEN ACCESS}

Edited by:

Ivan Baccelli,

Consiglio Nazionale delle Ricerche

(CNR), Italy

Reviewed by:

Emanuela Sani,

University of Edinburgh,

United Kingdom

Maria Raffaella Ercolano, Università degli Studi di Napoli

Federico II, Italy

*Correspondence:

Jolanta Floryszak-Wieczorek jolanta.floryszak@up.poznan.pl

Specialty section:

This article was submitted to

Plant Microbe Interactions,

a section of the journa

Frontiers in Plant Science

Received: 21 May 2018 Accepted: 02 August 2018

Published: 29 August 2018

Citation:

Meller B, Kuźnicki D,

Arasimowicz-Jelonek M, Deckert J

and Floryszak-Wieczorek J (2018)

BABA-Primed Histone Modifications

in Potato for Intergenerational

Resistance to Phytophthora infestans.

Front. Plant Sci. 9:1228.

doi: 10.3389/fpls.2018.01228
In this paper we analyzed $\beta$-aminobutyric acid (BABA)-primed epigenetic adjustment of potato cv. "Sarpo Mira" to Phytophthora infestans. The first stress-free generation of the potato genotype obtained from BABA-primed parent plants via tubers and seeds showed pronounced resistance to the pathogen, which was tuned with the transcriptional memory of SA-responsive genes. During the early priming phase before the triggering stress, we found robust bistable deposition of histone marks (H3K4me2 and H3K27me3) on the NPR1 (Non-expressor of PR genes) and the SNI1 gene (Suppressor of NPR1, Inducible), in which transcription antagonized silencing. Switchable chromatin states of these adverse systemic acquired resistance (SAR) regulators probably reprogrammed responsiveness of the $P R 1$ and $P R 2$ genes and contributed to stress imprinting. The elevated levels of heritable $\mathrm{H} 3 \mathrm{~K} 4 \mathrm{me} 2$ tag in the absence of transcription on SA-dependent genes in BABA-primed $\left(F_{0}\right)$ and its vegetative and generative progeny $\left(F_{1}\right)$ before pathogen challenge provided evidence for the epigenetic mark for intergenerational memory in potato. Moreover, our study revealed that histone acetylation was not critical for maintaining BABA-primed defense information until the plants were triggered with the virulent pathogen when rapid and boosted $P R$ s gene expression probably required histone acetyltransferase (HAT) activity both in $F_{0}$ and $F_{1}$ progeny.

Keywords: potato leaves, priming, late blight, histone modifications, intergenerational SAR

\section{INTRODUCTION}

Sometimes pathogen challenge or chemical treatment can trigger in plant a unique physiological state in which a plant is conditioned for the superactivation of defenses against new unfavorable conditions. In the primed state of defense the plant responds faster and activates more rapid defense responses when it is treated with a much more severe biotic stress. An important role 
of priming in systemic acquired resistance (SAR) has been supported by findings that primed cells are subject to chromatin modifications by epigenetic marks affecting plant defense (e.g., Conrath, 2011; Jaskiewicz et al., 2011; Mauch-Mani et al., 2017).

Both short- and long-lasting environmental experience of the parent can be imprinted and passed on to the next progenies as epigenetic memory in the form of sustained histone modifications and DNA methylation changes, linked to chromatin remodeling states that reprogram stress response gene expression. Specific histone modifications retained at altered levels after removal of the stimulus associated with persistent active or repressed chromatin states are proposed to act as heritable marks that manage re-establishment of the parental chromatin patterns on offspring chromosomes that might be kept through mitotic or meiotic cell divisions (Avramova, 2015).

Methylation of lysine residues on histone $\mathrm{H} 3$ and $\mathrm{H} 4$ by methyltransferases can positively or negatively affect gene transcription. Generally, methylation of $\mathrm{H} 3 \mathrm{~K} 4 \mathrm{me} 2 / 3$ and $\mathrm{H} 3 \mathrm{~K} 36 \mathrm{me} 2 / 3$ is associated with transcription-permissive chromatin (Xu et al., 2008; Zhang et al., 2009), while H3K27me3, H3K9me2, and $\mathrm{H} 4$ methylated especially at Lys-20 are found in transcription-repressive chromatin (Bernatavichute et al., 2008; Zhang, 2008; Dong and Weng, 2013). Histone methylation is mainly mediated by SET ffor Suppressor of variegation [SU(VAR)3-9], Enhancer of zeste $[\mathrm{E}(\mathrm{z})]$, and Trithorax $[\operatorname{Trx}]\}$ domain protein methyltransferase. However, the memory of the transcriptionally active/inactive chromatin status under stress responses is maintained by two classes of proteins, termed the Trithorax (TrxG) and the Polycomb (PcG) groups (Liu et al., 2010). Generally, it is accepted that Trithorax mediated H3K4me2/3 keeps genes responsive to stress in activation (e.g., Schuettengruber et al., 2011), and antagonizes PcG activity, which establishes H3K27me3 and H3K9me2 at the target genes (e.g., Köhler and Hennig, 2010; Audergon et al., 2015). Owing to their broad spectrum of preferred genes, evidence for the role of TrxG/PcG protein complexes in regulating defense priming responses currently remains incomplete (Derkacheva and Hennig, 2014; Kleinmanns and Schubert, 2014; Pu and Sung, 2015).

Apart from histone methylases described as "writers," the chromatin structure may be regulated by demethylases "erasers." The lysine-specific demethylase 1 (LSD1)-like proteins and a larger class of Jumonji C-domain (JmjC) proteins are engaged in the elimination of methyl groups from the methylated histones (Shi et al., 2004; Chen et al., 2011). The unstable equilibrium between histone methylation and demethylation is involved in many plant physiological (e.g., vernalization) or pathophysiological states (Köhler et al., 2012; Kim and Sung, 2014).

The histone methylation process is a major determinant of chromatin conformation, although histone acetylation/deacetylation also plays an important role in gene transcription. There are many histone-acetyltransferases (HATs) and-deacetylases (HDACs) with differing preferences for mutual cooperation. It is considered that acetylated histones are associated with active transcription, whereas the hypoacetylated histones are involved in gene repression (Boycheva et al., 2014). Especially in view of intergenerational or transgenerational memory, an epigenetic mark, in contrast to chromatin mark, remains at an altered level after removal of the stress stimulus but rather influences the future transcriptional activity of the training gene for enhanced stress resistance (Avramova, 2015; Lämke and Bäurle, 2017).

Generally it has been known that $\beta$-aminobutyric acid (BABA), a non-protein amino acid, is an effective chemical agent in long-term metabolic and epigenetic memory improving plant resistance to biotic stresses (Slaughter et al., 2012; Worrall et al., 2012; Luna et al., 2014; Floryszak-Wieczorek et al., 2015; Martínez-Aguilar et al., 2016; Wilkinson et al., 2018).

As it was experimentally documented in Arabidopsis, transgenerational resistance induced by BABA was lost in the second generation in the absence of a new BABA treatment (Slaughter et al., 2012), while transgenerational resistance induced by Pseudomonas syringae DC 3000 lasted over one stress-free generation (Luna et al., 2012). Moreover, the longlasting protection against the pathogen required the activity of the central immune regulator NPR1 (Non-expressor of $P R$ genes) and was associated with SA-responsive genes (Luna et al., 2012). In Arabidopsis thaliana the transcription factor WRKY70, while in potato WRKY1, are needed for full expression of SA-responsive PR-1,PR-2, and PR-5 genes (Li et al., 2004; Pieterse and Van Loon, 2004; Saubeau et al., 2016).

The activity of the SNI1 protein (Suppressor of NPR1, Inducible 1), a negative regulator of SAR required to dampen the expression of $P R$ genes, is also controlled by the epigenetic machinery. As it was shown by Mosher et al. (2006), more than $90 \%$ genes up-regulated in snil were benzothiadiazole S-methylester (BTH)-responsive and NPR1-dependent in Arabidopsis. Moreover, the study revealed that SNI1 inhibited SA-dependent transcription of the $P R-1$ gene through repression of histone $\mathrm{H} 3$ acetylation and methylation of histone $\mathrm{H} 3 \mathrm{~K} 4 \mathrm{me} 2$, while the sni1 mutant contained high levels of histone $\mathrm{H} 3$ acetylation and $\mathrm{H} 3 \mathrm{~K} 4 \mathrm{me} 2$ in the $P R-1$ promoter region.

A key to the understanding of the epigenetic background and duration of priming is provided by the ability to search for molecular mediators of the post-stress information. The research of Jaskiewicz et al. (2011) provided evidence that local inoculation of Arabidopsis leaves with Psm (P. syringae pv. maculicola) or BTH application modified the status of methylation ( $\mathrm{H} 3 \mathrm{~K} 4 \mathrm{me} 2 / 3)$ and acetylation (H3K9ac) at the promoter sequence of selected $W R K Y$ genes, which might create long-lasting post-stress memory in systemic leaves. In turn, López et al. (2011) based on Arabidopsis mutants blocked in RNAdirected DNA methylation revealed that primed responses are combined with post-translational histone modification, mainly by tri-methylation $(\mathrm{H} 3 \mathrm{~K} 4 \mathrm{me} 3)$ and acetylation $(\mathrm{H} 3 \mathrm{~K} 9 \mathrm{ac})$ at the promoter of the $P R 1$ gene.

Then, Luna et al. (2012) documented the effect of transgenerational priming in Arabidopsis conferred by the maintenance of a constant pressure of the virulent isolate of $P$. syringae, provided by the five times repeated inoculation in the parental generation. As a consequence, the first generation exhibited a primed state associated with the hypomethylated 
DNA status and chromatin modifications at the promoter of the PR1, WRKY6, and WRKY53 gene.

Other studies have reported that NPR1-independent resistance of Arabidopsis to $H$. arabidopsis was transient and might be reset within 2 weeks, in contrast to the NPR1-dependent long-lasting BABA-primed epigenetic regulation managed by methyltransferase activity of H3K9 (Luna et al., 2014).

In the presented paper our intention was to analyze BABAprimed epigenetic marks with the potential to create and harbor an intergenerational memory of potato resistance to virulent Phytophthora infestans. In this study potato (Solanum tuberosum L.) was used, a non-model, but very important crop plant every year being the most devastated by P. infestans (Mont.) de Bary as the causative agent of late blight disease. We selected stressresponsive genes (NPR1, SNI1, WRKY1, PR1, and PR2) highly induced in response to $P$. infestans, by analyzing among others the chromatin-modifying activities of the Trx/H3K4me2 and SUVH4/H3K27me3 link with the transcriptional memory of these genes. To the best of our knowledge so far there have been no published data on the epigenetic control for potato intergenerational resistance to $P$. infestans.

Until now, research has mainly focused on searching for the presence of epigenetic marks in the promoter region; however, we adopted the chromatin immunoprecipitation (ChIP) protocol to look at the gene body sequence of the stress-responsive genes. Genetic evidence revealed that in plants, in contrast to animals, H3 methylation marks (e.g., H3K4me1-3) are mainly located in the gene body (Zhang et al., 2009; Xiao et al., 2016), and $\mathrm{H} 3 \mathrm{~K} 4 \mathrm{me} 2 / 3$ in the gene body might contribute to the transcriptional memory in Arabidopsis (Alvarez-Venegas and Avramova, 2005; Ding et al., 2012; Kim et al., 2012). Moreover, when the presence of epigenetic tags was analyzed in different stress gene regions, the tendency of histone changes was similar or even less marked in the promoter rather than in the coding region of the gene (e.g., Shen et al., 2014; Crespo-Salvador et al., 2018).

\section{MATERIALS AND METHODS}

\section{Plant Material}

Sterile potato plant Solanum tuberosum L. cultivar "Sarpo Mira" (carrying the $R$ genes: $R 3 a, R 3 b, R 4, R p i-S m i r a 1$, and $R p i$ Smira2), obtained from the Potato Genebank (Plant Breeding and Acclimatization Institute - IHAR-PIB in Bonin) was initially derived from an in vitro tissue culture and kept in sterile soil in a phytochamber with $16 \mathrm{~h}$ of light $\left(180 \mu \mathrm{mol} \mathrm{m}{ }^{-2} \mathrm{~s}^{-1}\right)$ at $18 \pm 2^{\circ} \mathrm{C}$ and $60 \%$ humidity up to the stage of 10 leaves. Vegetative and generative descendants derived from tubers and seeds $\left(F_{1}\right)$ were obtained from unprimed and primed parental plants $\left(\mathrm{F}_{0}\right)$, respectively. The $\mathrm{F}_{1}$ plants were cultivated and inoculated under the same conditions as $\mathrm{F}_{0}$.

\section{Pathogen Culture}

Phytophthora infestans (Mont.) de Bary, virulent for "Sarpo Mira" (A1 mating type, race 1.2.3.4.6.7.10., isolate MP 977), was kindly supplied by the Plant Breeding and Acclimatization Institute
(IHAR), Młochów Research Centre, Poland. The pathogen was grown on a cereal-potato medium and transferred two times through the potato tuber before infection.

\section{Immunization With BABA Treatment and Challenged Inoculation}

The potato cv. "Sarpo Mira" was immunized by spraying potato leaves with $5 \mathrm{mM}$ of BABA ( $3 \mathrm{ml}$ per plant). BABA was delivered to the plant surface using an atomizer. The control of noninduced plants was sprayed with water (Floryszak-Wieczorek et al., 2015). At $72 \mathrm{~h}$ after immunization with BABA treatment, potato plants were challenge inoculated by spraying leaves with $5 \mathrm{ml}$ of the oomycete zoospore suspension at a concentration of $2.5 \times 10^{5}$ per $1 \mathrm{ml}$ of water. For the purpose of disease assessment inoculated plants were first kept for $12 \mathrm{~h}$ at $100 \%$ humidity and $18^{\circ} \mathrm{C}$. Next plants were moved to a growth chamber and they were kept under controlled conditions. The probes were collected at $0,1,3,6,24,48$, and $72 \mathrm{~h}$ after BABA treatment and 1, 3, 6,24 , and $48 \mathrm{~h}$ after $P$. infestans challenge inoculation. Progeny of unprimed and primed plants were challenge inoculated by $P$. infestans and probes were collected at 1, 3, 6, 24, and 48 hpi.

\section{Assessment of Disease Index}

The area affected by disease symptoms was assessed on potato leaves 5 day after inoculation with $P$. infestans based on the scale of area under disease progress (AUDP) from I to IV (James, 1971), which represented the percentage of leaf area covered by late blight symptoms ( $\mathrm{I}=1-9 \%$; II = 10-24\%; III = 25-49\%; IV $=50-100 \%)$. Disease symptoms were also determined during trypan blue staining of the $P$. infestans hyphae according to the assay proposed by Wilson and Coffey (1980). The AUDP was measured at parental $\mathrm{F}_{0}$ and $\mathrm{F}_{1}$ progeny plant using the open source ImageJ software.

\section{Gene Expression Analysis}

The RNA was extracted from $200 \mathrm{mg}$ of frozen leaf tissues using TriReagent (Sigma, United States). The obtained RNA was purified with the use of a Deoxyribonuclease Kit (Sigma, United States). For the reverse transcription $1 \mu \mathrm{g}$ of RNA from every experimental variant was processed with a Reverse Transcription Kit (Thermo Scientific Fermentas, United States). Real-time PCR was performed on a Piko Real Thermocycler (Thermo Fisher Scientific, United States). Primers for the investigated genes (CAF-1, H3, H4, HDAC, HAT, SUVH4, JMJ706, TrxG, NPR1, PR1, PR2, and SNI1) were designed by the Primer3 Output software or the PRIMER BLAST (Supplementary Table S1). All of them were based on available potato (or Solanaceae) cDNA sequences found in the NCBI (GenBank) or PGSC (Potato Genome Sequencing Consortium). The reaction mixture contained $0.1 \mu \mathrm{M}$ of each primer, $1 \mu \mathrm{l}$ of $5 \times$ diluted cDNA, $10 \mu \mathrm{l}$ of the Power SYBR Green PCR Master mix (Applied Biosystems) and DEPC treated water to the total volume of $20 \mu \mathrm{l}$. Reaction specificity was confirmed by the occurrence of one peak in the melting curve analysis. The data were normalized to the reference genes encoding the elongation factor (ef1 $\alpha, \mathrm{AB} 061263)$ and $18 S$ rRNA (X67238). 
The Ct values were determined with the use of a Real-time PCR Miner (Zhao and Fernald, 2005) and the relative gene expression was calculated with the use of the efficiency corrected calculation models presented in Pfaffl (Pfaffl, 2001; Tichopad et al., 2004).

\section{Chromatin Immunoprecipitation Assay}

ChIP was performed as previously described by Haring et al. (2007). Potato leaves (2 g) were fixed to crosslink protein-DNA interactions in a buffer with $1 \%$ formaldehyde and frozen at $-80^{\circ} \mathrm{C}$. One day before chromatin extraction, agarose A beads (Merck Millipore) were blocked and resuspended in the ChIP dilution buffer with the following specific antibodies: H3K4me2 (EMD Millipore; cat.-no 04-790), H3K9me2 (EMD Millipore; cat.-no. 07-441), or H3K27me3 (EMD Millipore; cat.-no. 07449 ), and incubated overnight on a rotating wheel at $4^{\circ} \mathrm{C}$ to promote antibody attachment to the beads. Chromatin was isolated according to the protocol (Haring et al., 2007; Komar et al., 2016) and sheared by sonication. The resolution obtained by the ChIP procedure was determined by the size of the chromatin fragments used as input material. Ideally, the bulk of chromatin was sonicated to a length between 250 and $750 \mathrm{bp}$. Any insoluble materials were precipitated by the preclearing step, followed by overnight probe incubation with the antibody. Simultaneously "Input" probes (sonicated chromatin without the antibody) were precleared at blocked protein Agarose A beads. The next step consisted of chromatin reverse crosslinking. Then probes were reverse crosslinked by overnight incubation with $\mathrm{NaCl}$ and $20 \% \mathrm{SDS}$ at $65^{\circ} \mathrm{C}$ with shaking. The next step was adding proteinase $\mathrm{K}$ to digest proteins, release and clean DNA. Samples were purified using a commercial spin column kit (Promega). The final step consisted of measuring the abundance of binding sites in the immunoprecipitated DNA by qPCR. The reaction mixture contained $0.1 \mu \mathrm{M}$ of each primer, 2$5 \mu \mathrm{l}$ purified DNA, $10 \mu \mathrm{l}$ of the Power SYBR Green PCR Master mix (Applied Biosystems) and DEPC treated water to the total volume of $25 \mu \mathrm{l}$. Reaction specificity was confirmed by the occurrence of one peak in the melting curve analysis. Primers for the investigated genes (NPR1, PR1, PR2, SNI, and WRKY1) were designed by the Primer3 Output software. Data were analyzed by the "\% of input method" (Komar et al., 2016). Raw Ct values were obtained after real-time qPCR reactions and adapted for input samples by subtracting a value of logarithm base 2 from the fraction of the input. The percentage of the input was calculated by applying the following formula: $\%$ input $=100 * 2^{\text {[adjustedinput }-\mathrm{Ct}(\text { sample })]}$.

\section{Statistical Analysis}

All the results were based on three independent experiments. For each experiment, at least three biologically replicated samples were collected, each consisting of leaves from six plants. For each experiment, means of the obtained values were calculated along with standard deviations. The analysis of variance was conducted and the least significant differences (LSDs) between means were determined using Tukey's test at the level of significance $\alpha=0.005$.

\section{RESULTS}

\section{BABA-Primed Intergenerational Resistance to Phytophthora infestans}

Priming efficiency of $5 \mathrm{mM}$ BABA in triggering SAR responses in "Sarpo Mira" was determined on the basis of the disease index assay, i.e., the development of potato late blight symptoms in the parental line $\left(\mathrm{F}_{0}\right)$ and its successive progenies $\left(\mathrm{F}_{1}\right)$, according to the experimental model shown in Figure 1A. Three days after BABA treatment $(72 \mathrm{~h})$ plants were inoculated and the rate of potato leaves colonized by $P$. infestans was scored at day 5 after the challenge. All the observed changes were referred to the BABA-unprimed plants, i.e., potato not subjected to priming or only inoculated with a virulent pathogen. The index of disease development in potato leaves represents the percentage of leaf area covered by late blight symptoms, respectively, classifying them into four categories according to the percentage of leaf tissue colonized by the pathogen. In the parental line $\left(\mathrm{F}_{0}\right)$ supplied with BABA the late blight disease limitation was very high, resulting in approx. $70 \%$ disease spot reduction, compared to the unprimed one (Figure 1B). Less than $10 \%$ of potato leaf area was occupied by non-spreading late blight spots.

To determine the duration of priming state, the vegetative progeny of primed plants derived from tubers and generative progeny from seeds were analyzed. However, it should be underlined that the parental line $\left(\mathrm{F}_{0}\right)$ was treated once with $5 \mathrm{mM}$ BABA. This means that its progeny plants $\left(\mathrm{F}_{1}\right)$ grown from tubers or seeds were not again treated with BABA, but only inoculated with $P$. infestans at the stage of 10 compound leaves. Our results showed that the BABA-primed state for effective defense of "Sarpo Mira" was transmitted from parents to their vegetative and generative progenies as enhanced resistance to the pathogen. Plants $\left(F_{1}\right)$ grown from tubers previously activated by BABA showed an important reduction of late blight symptoms (Figure 1C). Inoculated potato leaves from $F_{1}$ plants had on average significantly smaller lesion diameters (up to $9 \%$ and $24 \%$ of the leaf area) than those from the unprimed and $P$. infestans inoculated ones.

Similarly, a considerable decrease (approx. 50\%) of disease spot area compared to the infected unprimed leaves was found in the generative descendants not exposed to an additional stimulus (Figure 1D). These data showed that the offspring of BABAprimed potato, subjected to the same-generation priming, over one stress-free generation maintained an enhanced resistance to $P$. infestans.

\section{Transcriptional Reprogramming of SA-Dependent Genes After BABA Treatment}

Generally, $P R$ s transcript levels were very low or undetectable in potato plants not exposed to BABA. In turn, BABA pretreatment resulted in a slight and transient up-regulation of the mRNA transcript for $P R 1$ and $P R 2$, which returned after $48 \mathrm{~h}$ to nearly basal levels (Figure 2A). In contrast, 
A

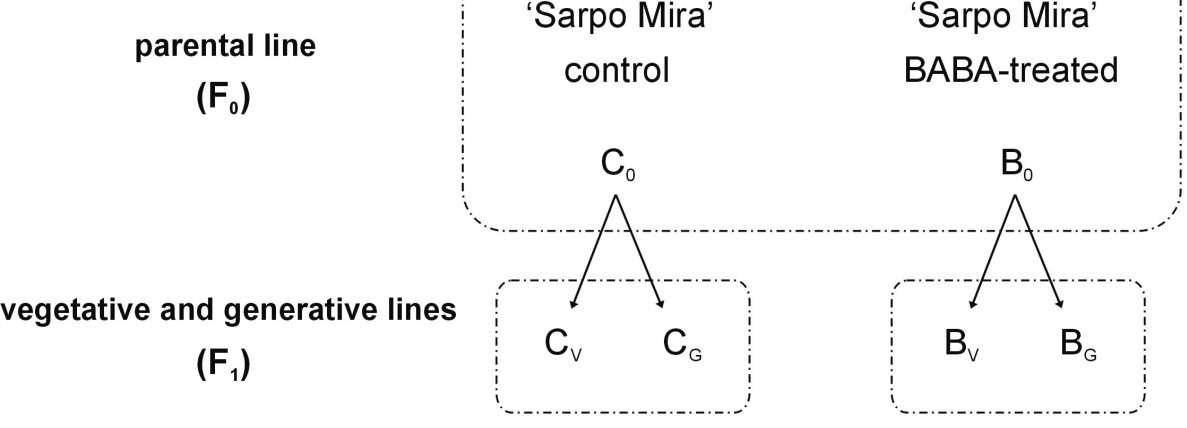

B

parental generation $\mathrm{F}_{0}$

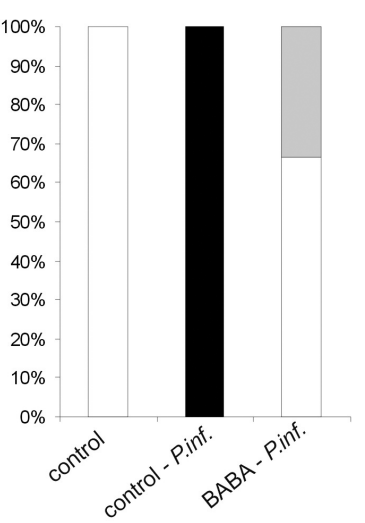

C

vegetative descendants $F_{1}$

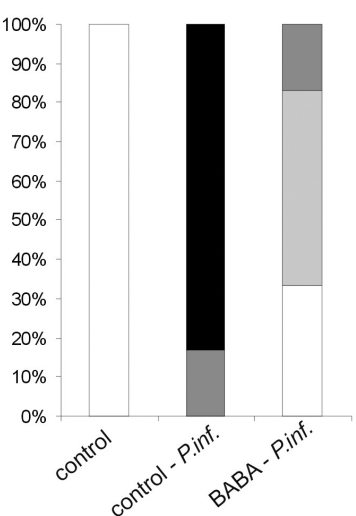

D

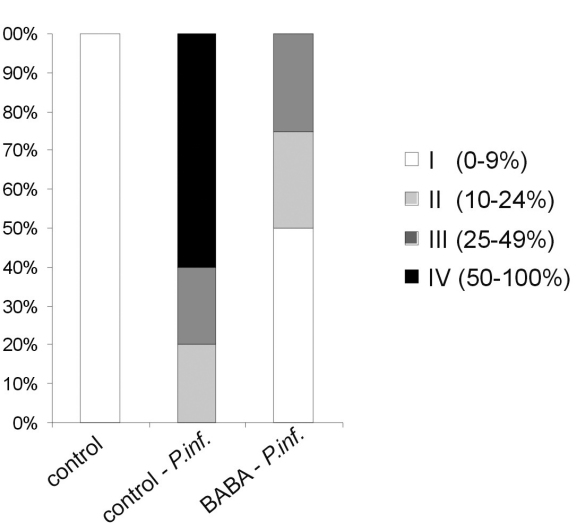

FIGURE 1 | Intergenerational resistance in potato progeny unprimed and BABA-primed to $P$. infestans. Schematic representation of the experimental design (A) the parental line of "Sarpo Mira" potato genotype $\left(F_{0}\right)$ was treated once with $5 \mathrm{mM}$ BABA $\left(B_{0}\right)$. The progeny $\left(F_{1}\right)$ grown from tubers or seeds were not again treated with BABA, but only inoculated with $P$. infestans - at the stage of 10 compound leaves. Abbreviations mean: the parental $F_{0}$ line BABA-primed - $B_{0}$, the offspring of primed plants of the vegetative $F_{1}$ line $-B_{V}$, and the generative $F_{1}$ line $-B_{G}$. Three days after BABA-exposure or water treatment $\left(C_{0}\right)$ potato leaves were challenged with $P$. infestans and disease development was assayed at day 5 after $P$. infestans inoculation (dpi). BABA-induced resistance against $P$. infestans in the parental $\left(F_{0}\right)$ line (B), intergenerational resistance in the vegetative $F_{1}$ progeny $(\mathbf{C})$, and in the generative $F_{1}$ progeny (D). Disease index is based on a $1-4$ point scale, which represents the percentage of leaf area covered by late blight symptoms. Values represent means of at least three independent experiments, each with at least three biological replicates. Asterisks indicate values that differ significantly from unprimed (water treated) or unprimed and $P$. infestans inoculated potato leaves at $P<0.05$ $(*)$, respectively.

the sequential treatment of potato plants with BABA followed by $P$. infestans provided data on stress imprint activation, facilitating the acquisition of a competence to react faster and stronger after challenge inoculation, in the form of a potentiated rise in $P R 1$ and $P R 2$ levels of the gene expression upon pathogen treatment. An enhanced $P R$ transcript accumulation was reflected in the increase of basal resistance to the late blight disease compared to unprimed, but inoculated potato.

Moreover, our data revealed that the priming stimulus was transmitted into the next generation in the form of intergenerational stress memory. Since descendants of the primed potato were derived from tubers or seeds, they showed a faster and higher transcription of $P R 1$ and $P R 2$ correlated with an enhanced intergenerational resistance to $P$. infestans in comparison to the inoculated progeny of unprimed plants (Figures 2B,C).

\section{Priming for Defense Is Supported by Enhanced Expression of both $\mathrm{H3}, \mathrm{H} 4$, and CAF-1 Histone Chaperon Genes in $F_{0}$ Potato Progeny}

To assess whether the effective priming observed in the BABAtreated potato and its progeny was due to an epigenetic regulation for the heritable defense we focused on exploring BABA-primed parental changes of histone modifications, which might be potentially associated with reprogramming of gene expression toward switching on and retention of information on previous stress exposure.

Potato leaves pretreated with BABA showed sensitization to the $H 3$ and $H 4$ genes during the maintenance of the priming phase, and thus generated an enhanced expression of these genes, starting from 1 to $3 \mathrm{~h}$ in $\mathrm{H} 3$ and from 1 to $24 \mathrm{~h}$ in $\mathrm{H} 4$ after induction, respectively (Figures $3 \mathbf{A}, \mathbf{B}$ ). 
A

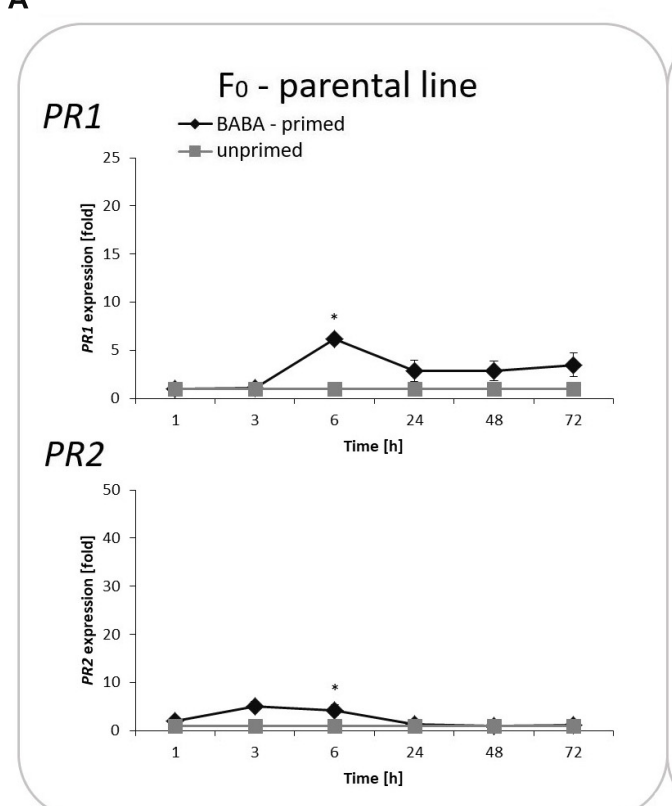

C

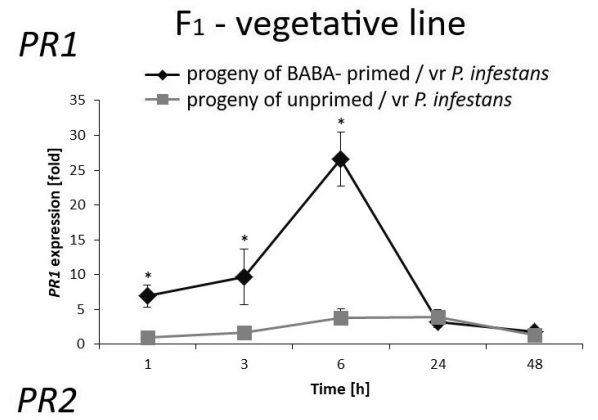

PR2

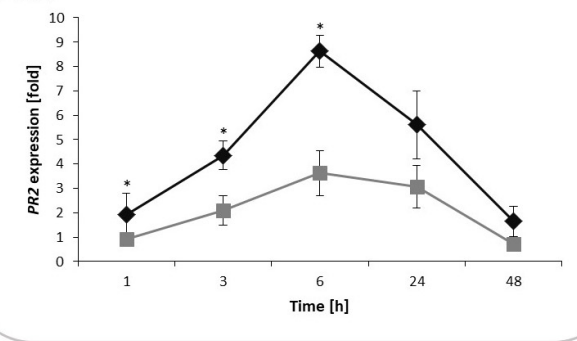

B
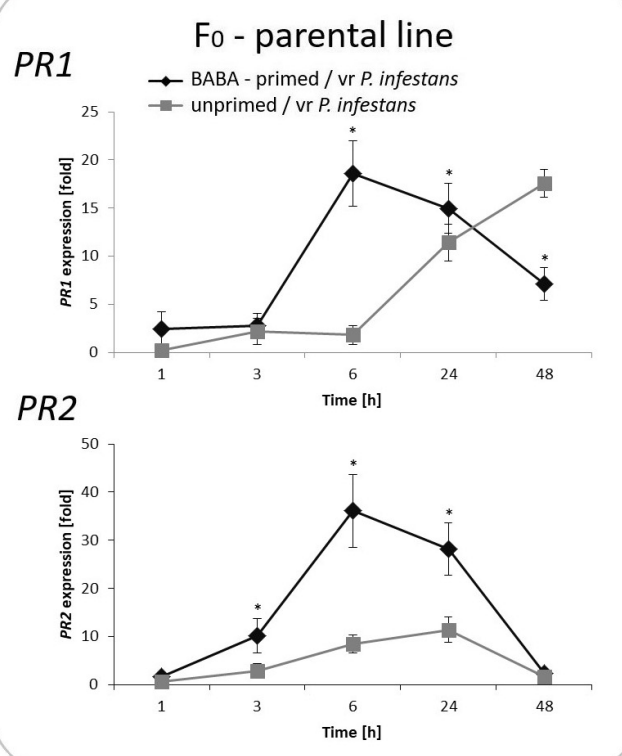

D
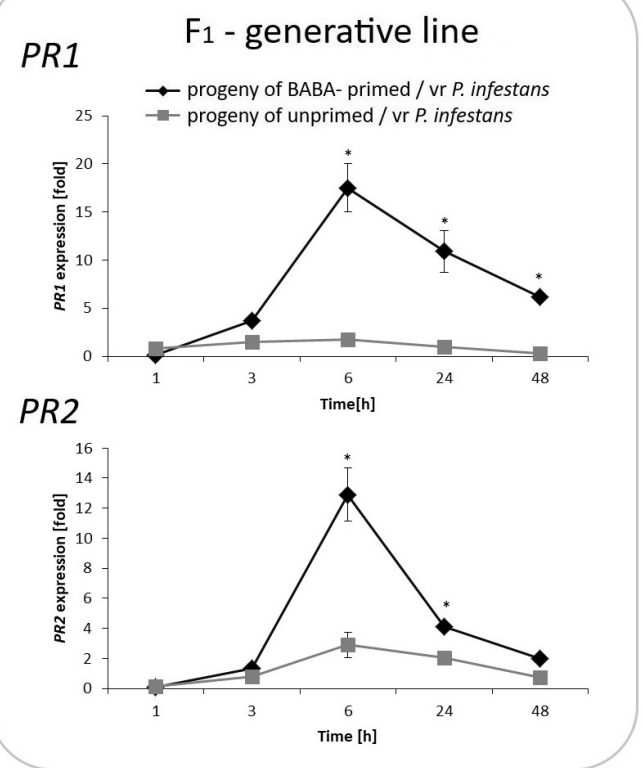

FIGURE 2 | Treatment with BABA reprograms SA-dependent gene transcription. The RT-qPCR analysis of $P R 1$ and $P R 2$ gene expression in BABA primed leaves of potato plants followed by challenge inoculation with $P$. infestans (at $72 \mathrm{~h}$ after BABA treatment) in parental line $\mathrm{F}_{0}$ (A,B). Analyses were performed at $0-48 \mathrm{~h}$ after $5 \mathrm{mM}$ BABA exposure and 1-48 hpi after challenge inoculation. Transcriptional priming of $P R 1$ and $P R 2$ gene expression after $P$. infestans inoculation in the offspring of BABA-primed $F_{1}$ - vegetative line (C), and $F_{1}$ - generative line (D). Light columns refer to unprimed, while dark columns - to primed plant progeny. Values represent means of data \pm SD of at least three independent experiments. Asterisks indicate values that differ significantly from unprimed (water treated) or unprimed and $P$. infestans inoculated potato leaves at $P<0.05\left(^{*}\right)$, respectively.

Moreover, the mRNA transcripts for both $\mathrm{H3}$ and $\mathrm{H} 4$ were again early up-regulated during the first day after inoculation and afterward systematically diminished in the following timeperiods after challenge inoculation compared to unprimed plants undergoing inoculation. Interestingly, the CAF-1 gene of the histone chaperon protein revealed a clear correlation with the biphasic changes in $\mathrm{H} 3$ and $\mathrm{H} 4$ gene expression upon BABA and pathogen stress exposure in $\mathrm{F}_{0}$ potato plants (Figure 3C).

Moreover, CAF-1 transcription levels were also much higher after inoculation with $P$. infestans in $\mathrm{F}_{1}$ offspring plants derived from tubers or seeds compared with the inoculated progeny of unprimed plants (Supplementary Figures S1A,B). 
A

\section{H3}

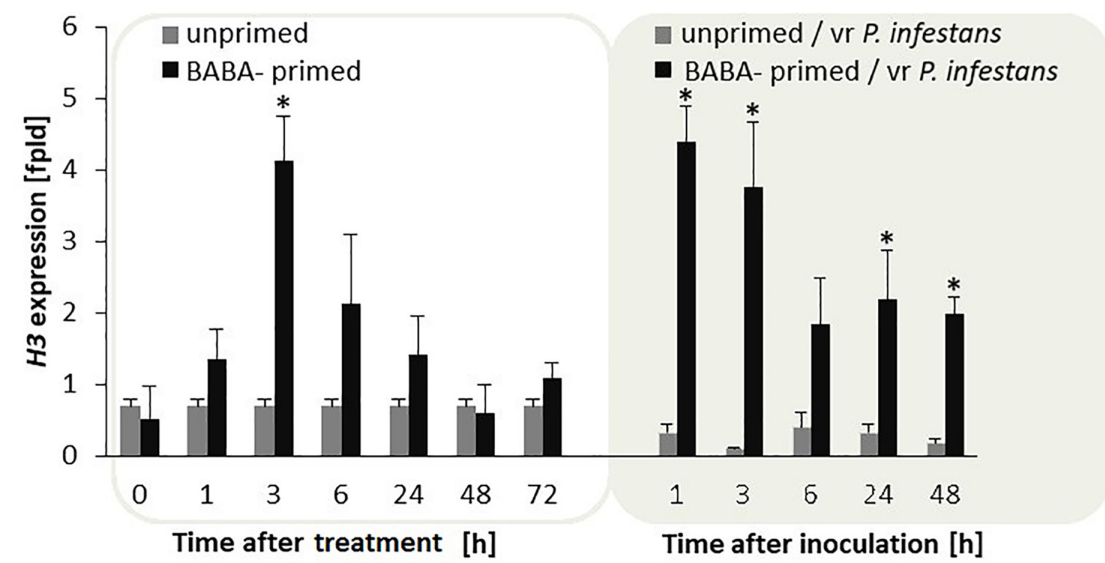

B

\section{H4}

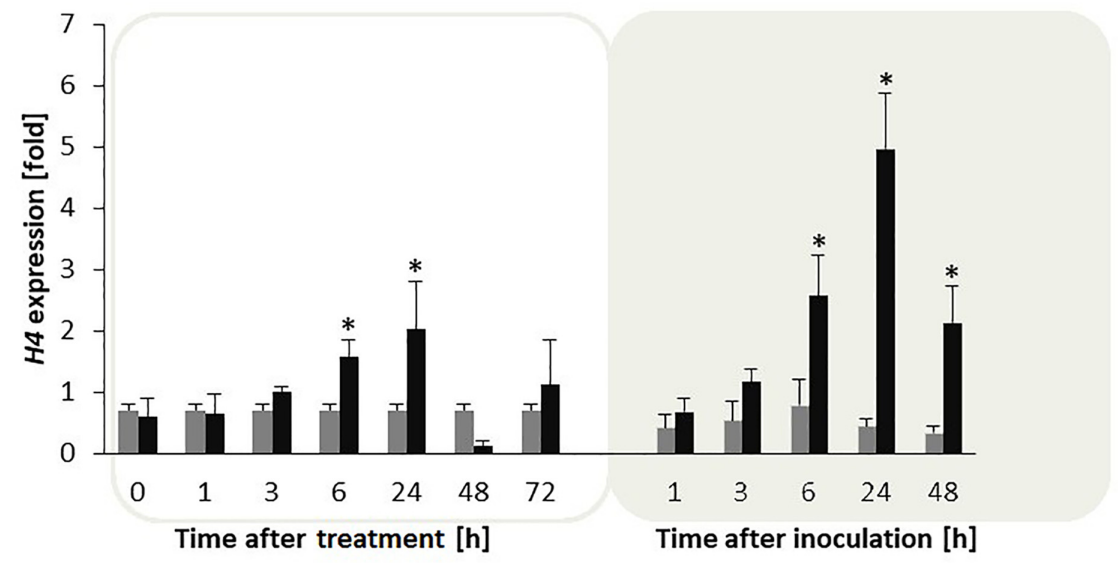

C

\section{CAF1}

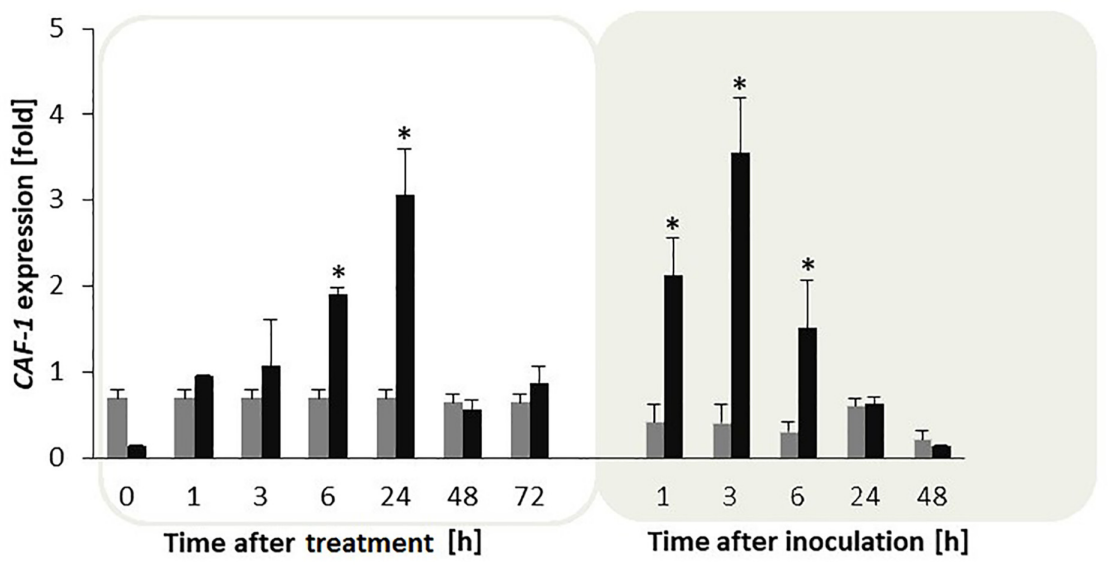

FIGURE 3 | Priming for defense is supported by enhanced expression of both $\mathrm{H3}, \mathrm{H} 4$, and CAF-1 histone chaperon genes in $\mathrm{F}_{0}$ potato progeny. The qRT-PCR analysis of $H_{3}$ (A), $H_{4}$ (B), and CAF1 (C) gene expression in BABA-primed leaves of potato plants followed by challenge inoculation with $P$. infestans (at $72 \mathrm{~h}$ after BABA treatment). Analyses were performed at 0-48 h after $5 \mathrm{mM}$ BABA exposure (white background) and 1-48 hpi after challenge inoculation (gray background). Light columns refer to unprimed, while dark columns - to primed plants. Values represent means of data \pm SD of at least three independent experiments. Asterisks indicate values that differ significantly from unprimed (water treated) or unprimed and $P$. infestans inoculated potato leaves at $P<0.05(*)$, respectively. 
A

HDAC

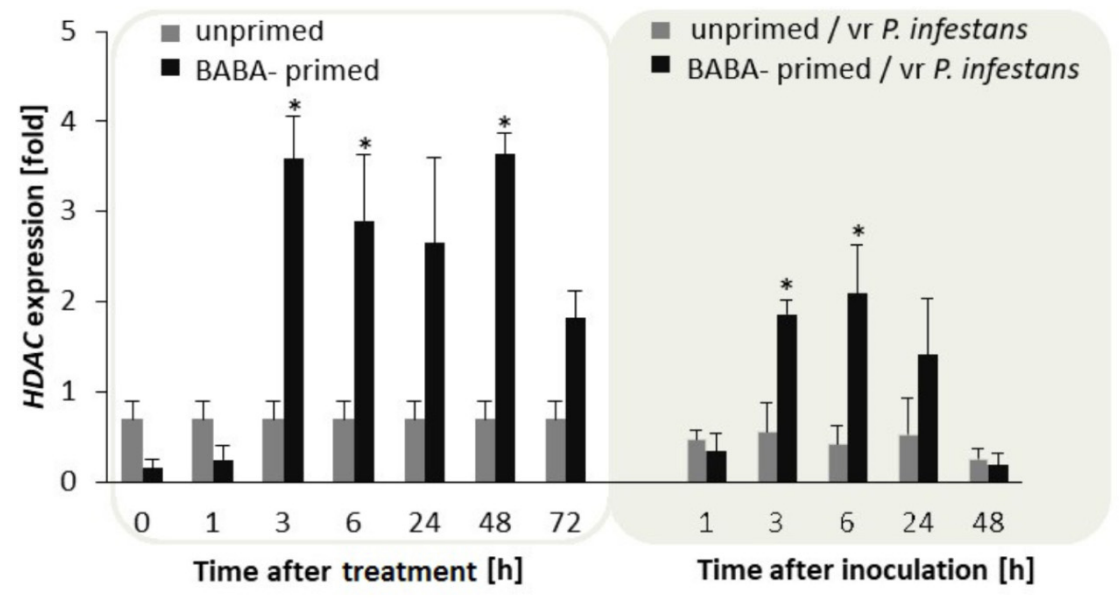

B HAT

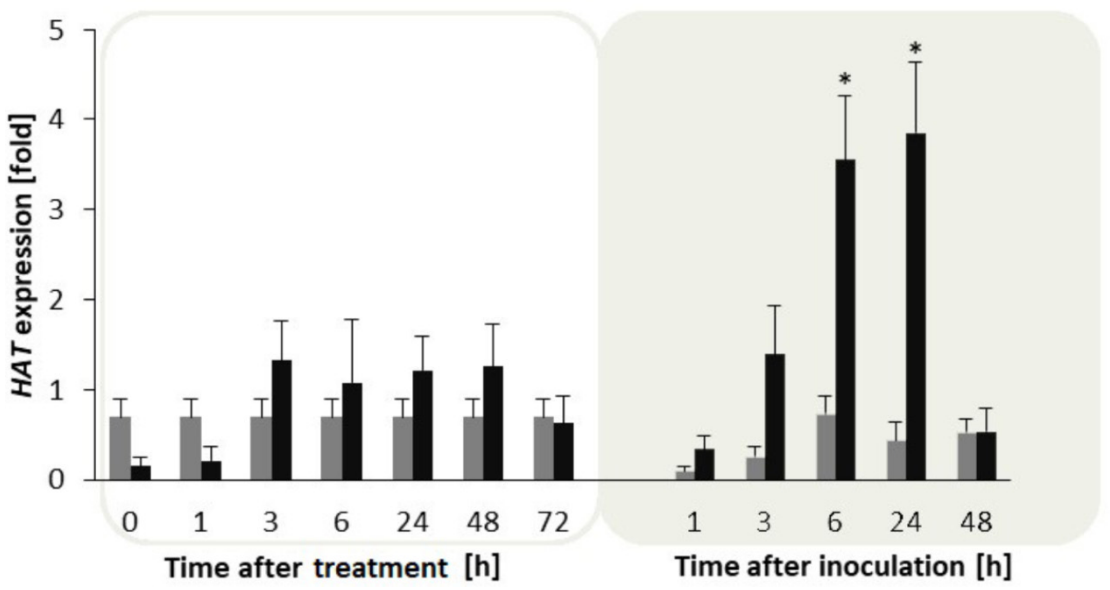

FIGURE 4 | Expression patterns of histone acetylation and deacetylation upon exposure to BABA and biotic stress. Transcriptional analysis of HDAC (A) and HAT (B) gene expression in BABA-primed leaves of potato plants followed by challenge inoculation with $P$. infestans (at $72 \mathrm{~h}$ after BABA treatment). Analyses were performed at 0-48 h after $5 \mathrm{mM}$ BABA exposure (white background) and 1-48 hpi after challenge inoculation (gray background). Light columns refer to unprimed, while dark columns - to primed plants. Values represent means of data \pm SD of at least three independent experiments. Asterisks indicate values that differ significantly from unprimed (water treated) or unprimed and P. infestans inoculated potato leaves at $P<0.05\left(^{*}\right)$, respectively.

\section{Involvement of Histone Acetylation and Deacetylation in BABA-Primed Defense Information}

To examine the flexibility of histone lysine acetylation in primed potato we analyzed gene expression of HAT and HDAC during the establishment of the priming and after triggering stress in the $\mathrm{F}_{0}$ potato line. An antagonistic tendency of $H A T$ and $H D A C$ transcriptional activities was observed (Figures 4A,B). Thus in BABA-treated potato leaves the relatively low HAT transcription levels changed after the challenge by the virulent pathogen when HAT gene expression gradually increased in successive hours after inoculation. In contrast, BABA treatment resulted in enhanced transcriptional priming of $H D A C$ gene activity before inoculation preceding downregulation of this gene upon challenge with the oomycete pathogen.

In conclusion, the $\mathrm{H} 3$ acetylation seemed to be non-decisive for maintaining BABA-primed defense imprint, whereas the situation changed in plants triggered with pathogen when rapid and boosted $P R$ s gene expressions might need HAT activity. In contrast to histone deacetylase, HAT transcription was also significantly intensified after challenge inoculation with $P$. infestans in $\mathrm{F}_{1}$ progeny plants (Supplementary Figures S2A,B). It is worth emphasizing that BABA triggered HAT expression only upon pathogen inoculation both in $\mathrm{F}_{0}$ and $\mathrm{F}_{1}$ progeny. Here, we found that the primed state in potato was tuned with the transcriptional memory of post-infection HAT 
activation in the next generation without an additional BABA treatment.

\section{Histone Lysine Methyltransferases and Demethylase Are Required for BABA-Triggered Immunity}

BABA turned out to be an effective factor in upregulation of the $\operatorname{Tr} x G$ gene in potato leaves. The $\operatorname{Tr} x G$ gene was first strongly (approx. 7 -fold) potentiated at $3 \mathrm{~h}$, and then the activity diminished slightly in the following hours after the BABA treatment and challenge inoculation. Nevertheless, generally $\operatorname{Trx} G$ transcript accumulation was much more abundant in induced rather than the unprimed and/or inoculated leaves (Figure 5A). An independent analysis of the SUVH4 time expression pattern revealed a rather opposite effect to that of $\operatorname{Tr} x G$ in the form of rapid growth (peaking at $1 \mathrm{~h}$ ) followed by a short decrease (from 3 to $6 \mathrm{~h}$ ) and repeated increase in SUVH4 gene expression at the successive time points after BABA had been supplied (Figure 5B). Further data showed that $\operatorname{Tr} x G$ and SUVH4 were not so differentially expressed upon pathogen inoculation, initially giving enhanced gene activation. However, in $\mathrm{F}_{1}$ descendants of the primed potato, both levels of $\operatorname{Tr} x G$ and SUVH4 transcripts were significantly higher than in unprimed ones upon the triggering stress (Supplementary Figures S3A,B, S4A,B).

In turn, JMJ706 belonging to the family of demethylases reverses $\mathrm{H} 3 \mathrm{~K} 9 \mathrm{me} 2$, was induced mainly upon BABA application and revealed gene upregulation (up to 4-fold increase) starting from 6 to $24 \mathrm{~h}$ after the inducer treatment, while it again sharply increased early upon pathogen stress exposure (Figure 5C). Interestingly, a similar, but much more marked increase in JMJ706 transcription was found after $P$. infestans inoculation in plants derived from primed parents (F1 line) produced both from tubers and seeds (Supplementary Figures S3C, S4C).

\section{Tight Balance Between Antagonistic Histone Marks on NPR1 and SNI1 Genes During the Priming Phase}

Next, we attempted to analyze specific histone modifications in the form of methylation at the lysine residue 4, 9 and 27 on histone $\mathrm{H} 3$ (H3K4me2, H3K9me2, and H3K27me3) on the NPR1 and SNI1 genes coding positive and negative regulators of SAR.

BABA induced an early (at $3 \mathrm{~h}$ ) and significant increase in the $\mathrm{H} 3 \mathrm{~K} 4 \mathrm{me} 2$ level on NPR1, associated with an enhanced gene transcription at the same time point after inducer treatment (Figures 6A,C). In turn, the H3K27me3 mark, initially being in reduced occupancy on NPR1, systematically increased (peaked at $48 \mathrm{~h}$ ) after BABA supply and was tuned with downregulation of NPR1 gene expression.

The time-dependent opposite tendency of histone methylation tags was found on the SNI1 gene sequence (Figures $6 \mathbf{B}, \mathbf{C}$ ). The initially high accumulation of the H3K27me3 mark with a repressive level of SNI1 transcription changed in the consecutive hours after induction and revealed abundant H3K4me2 occupancy under an enhanced SNI1 gene expression (at 48-72 h). Interestingly, at the same hours, NPR1 gene expression underwent downregulation. Results showed that epigenetic regulation of NPR1/SNI1 was probably needed for tuning the transcriptional activity of SA-responsive genes for enhanced defense when establishing the priming phenomenon in potato.

BABA-exposure also resulted in high $\mathrm{H} 3 \mathrm{~K} 9 \mathrm{me} 2$ levels on the NPR1 gene loci appearing one time-point earlier (at $48 \mathrm{~h}$ ) and preceding a strong increase (up to 15-fold) of this mark on the SNI1 gene body at $72 \mathrm{~h}$ after induction (Figures 6A,B).

\section{Searching for the Epigenetic Mark on SA-Dependent Genes in Response to BABA-Priming}

Then, we focused on WRKY1 and two stress-responsive genes, $P R 1$ and $P R 2$, with the transcriptional potential to store and maintain information on a previous stimulus for future use. As it was shown earlier (Figure 2), PR1 and PR2 as stress memory genes possess an ability, both in the parental and descendant lines, to produce significantly faster and higher levels of the transcript during the second triggering stress compared to the level in the first stimulus treatment. Previously it was found that WRKY1 gene expression goes hand in hand with PR1 transcription (paper under review). In order to find an epigenetic mark associated with transcriptional memory, we analyzed changes and durability of H3K4me2 and H3K9me2 occupancy on these genes during a priming phase and before the pathogen challenge in $\mathrm{F}_{0}$ and $\mathrm{F}_{1}$ lines of potato.

BABA pretreatment early induced a higher deposition of the H3K4me2 mark on the coding sequence of WRKY1, PR1, and $P R 2$, compared to unprimed plants (Figures 7A-C). The elevated levels of $\mathrm{H} 3 \mathrm{~K} 4 \mathrm{me} 2$ as the effect of the priming stimulus preceded a low and transient activation of $P R 1$ and $P R 2$ gene expression (Figure 2A). Importantly, before the pathogen stress enrichment of H3K4me2 occupancy was found on the gene body of WRKY1, PR1, and PR2 in primed plants of the parental line $\left(\mathrm{F}_{0}\right)$ and even more abundant in their descendants $\left(\mathrm{F}_{1}\right)$ when the genes remained inactive or presented low transcription. Thus, the $\mathrm{H} 3 \mathrm{~K} 4 \mathrm{me} 2$ tag might be regarded as a heritable mark for intergenerational regulation of resistance in potato.

Independently, we provided evidence that BABA application also modified the methylation status of $\mathrm{H} 3 \mathrm{~K} 9 \mathrm{me} 2$ on the coding sequence of analyzed genes in parents and mostly in their offspring, which might also create a long-lasting post-stress memory in potato plants (Figures 7A-C).

\section{DISCUSSION}

Despite abundant reports on BABA-induced immune or adaptive defense responses against environmental challenges in the same plant generation, experimental research on BABA-primed stress imprint extending from one stressed plant generation to at least the first stress-free descendants has been scarce (Luna et al., 2012; Slaughter et al., 2012; Floryszak-Wieczorek et al., 2015; MartínezAguilar et al., 2016).

Our experiment clearly showed that the used potato genotype exposed to BABA displayed improved disease resistance and 


\section{A}

\section{$\operatorname{Tr} x G$}

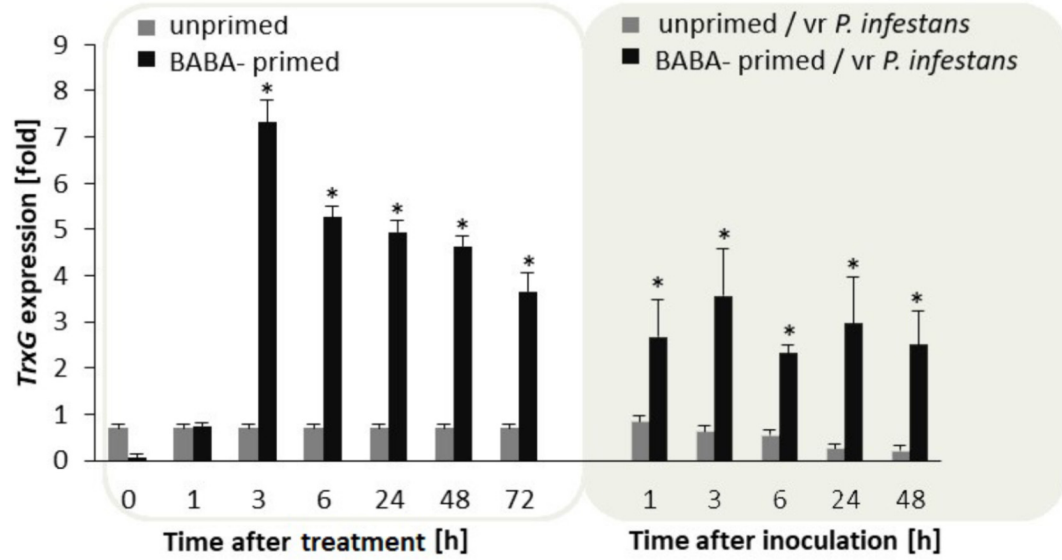

B

SUVH4

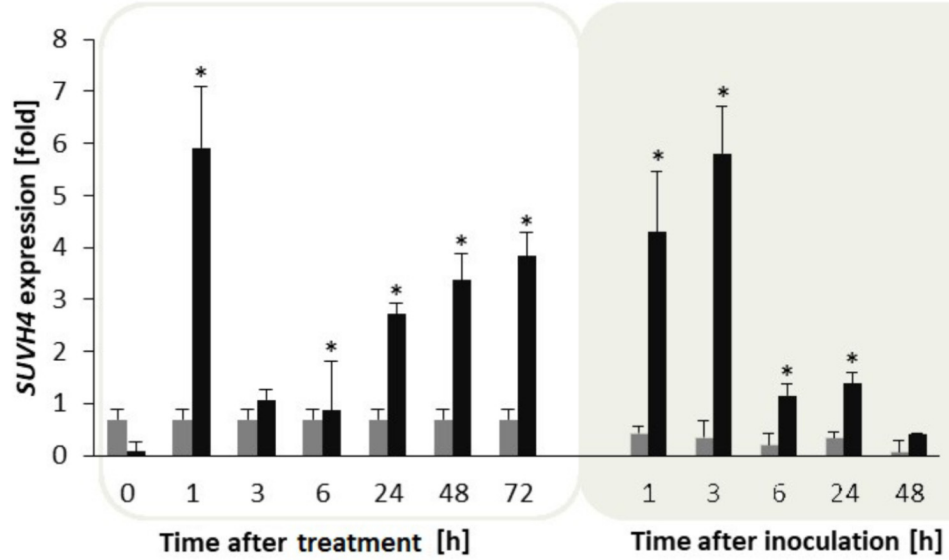

C

JMJ706

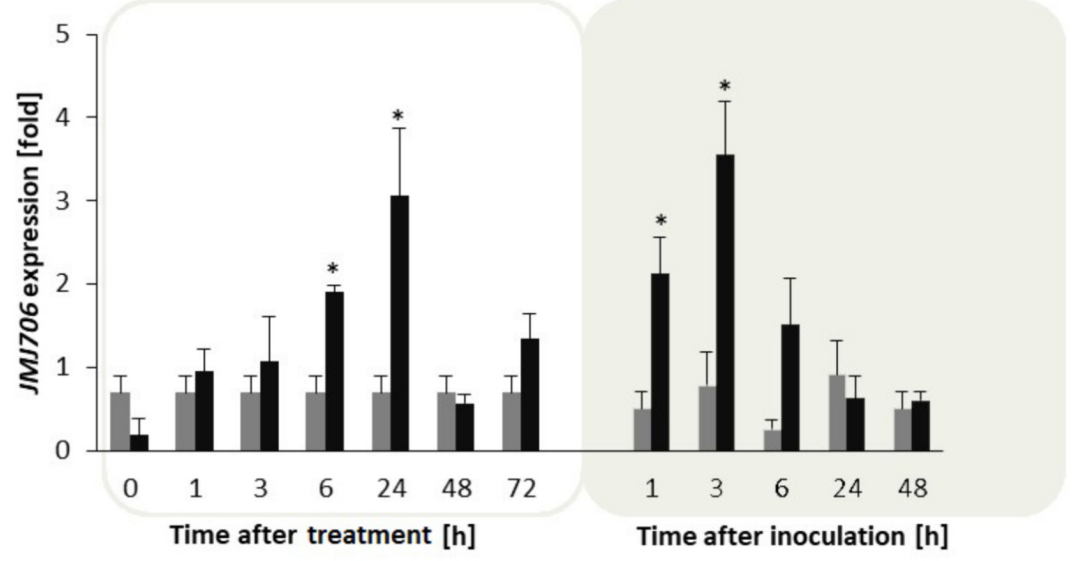

FIGURE 5 | Histone lysine methyltransferases and demethylase are required for BABA-triggered immunity. Transcription changes in TrXG, SUVH4, and JMJ706 gene expression in BABA-primed leaves of $F_{0}$ potato plants followed by challenge inoculation with $P$. infestans (A). Analyses were performed at 1-48 h after $5 \mathrm{mM}$ BABA exposure (white background) and 1-48 hpi after challenge inoculation (gray background). Transcriptional priming of TrxG, SUVH4, and JMJ706 gene expression after $P$. infestans inoculation in the offspring of BABA-primed $F_{1}$ - vegetative line (B), and $F_{1}$ - generative line (C). Light columns refer to unprimed, while dark columns - to primed plants progeny. Values represent means of data $\pm S D$ of at least three independent experiments. Asterisks indicate values that differ significantly from unprimed (water treated) or unprimed and $P$. infestans inoculated potato leaves at $P<0.05\left(^{*}\right)$, respectively. 


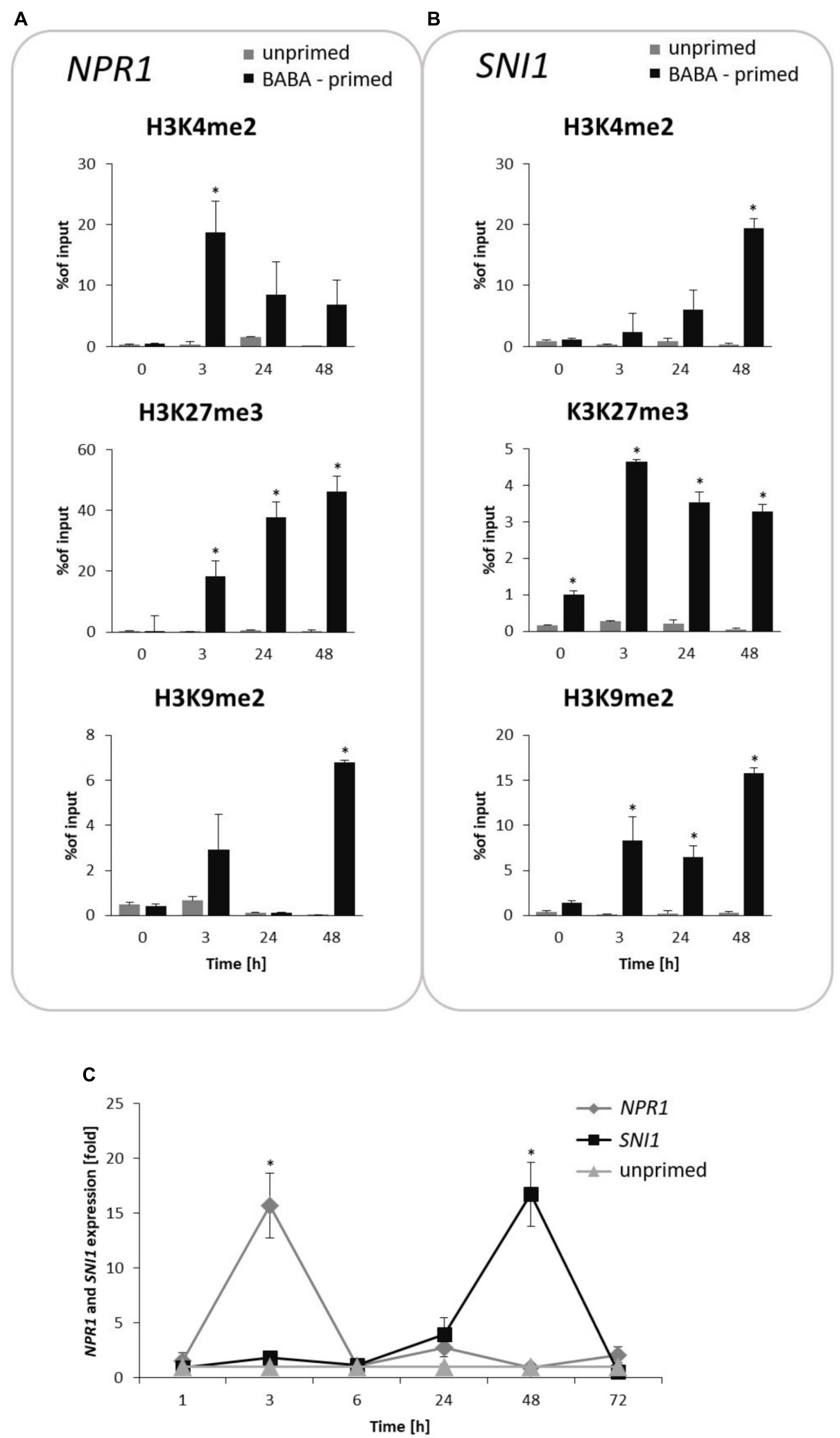

FIGURE 6 | Switchable deposition of chromatin marks on the NPR1 and SN/1 gene, in which transcription antagonized silencing. Time-dependent H3 methylation profiles on NPR1 (A) and SN/1 (B) and their transcript levels (C) in the prime state before the triggering stress. ChIP-qPCR and RT-qPCR analysis of NPR1 and SN/1 gene expression were performed at 3, 24, 48, and $72 \mathrm{~h}$ after $5 \mathrm{mM}$ BABA treatment. Each experiment was repeated three times and the data are presented as percentages of input DNA. Asterisks indicate values that differ significantly from unprimed (water treated) potato leaves at $P<0.05{ }^{(*)}$. 
A

WRKY1

H3K4me2

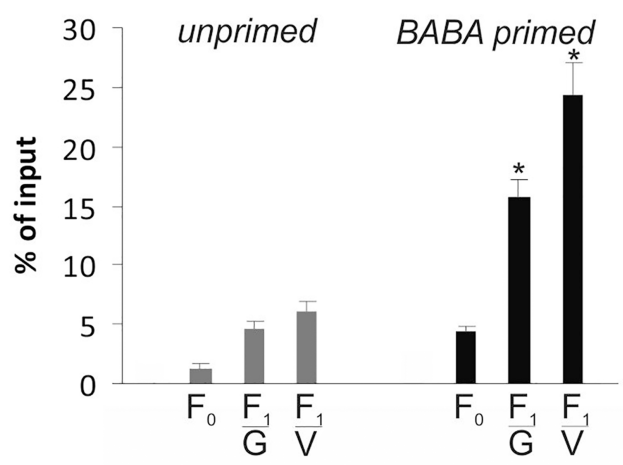

B

PR1

H3K4me2

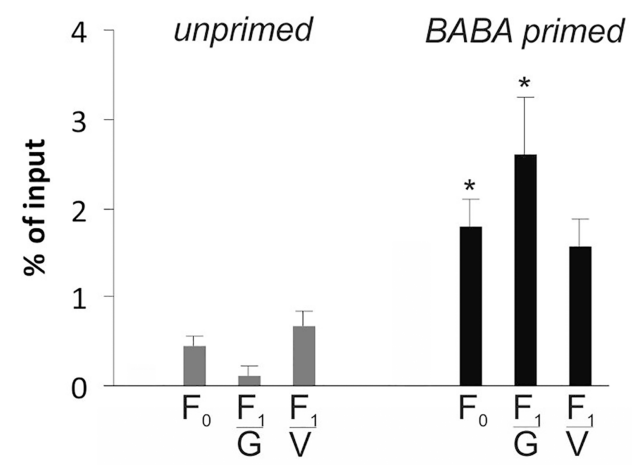

C

\section{PR2}

H3K4me2

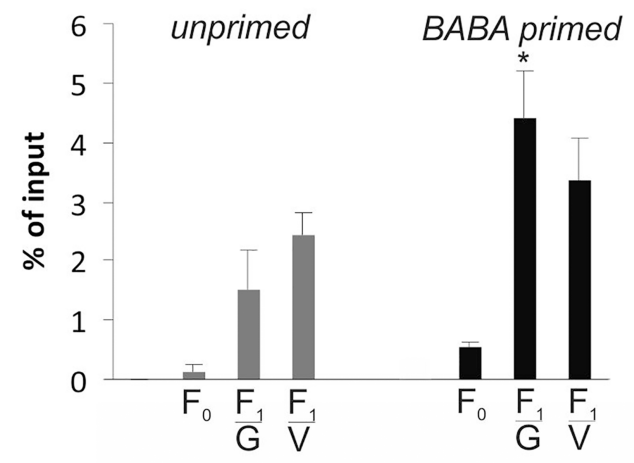

H3K9me2

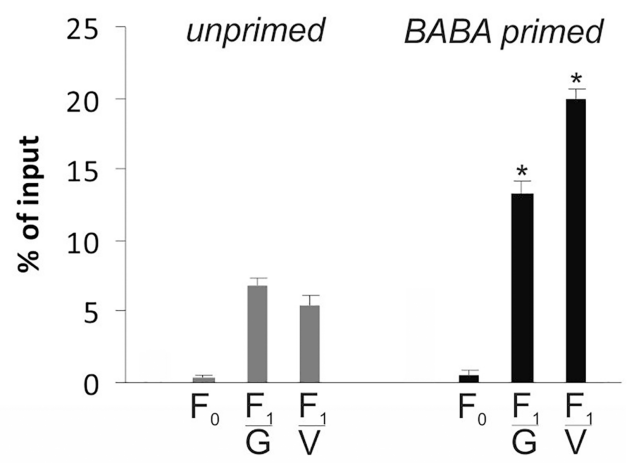

H3K9me2

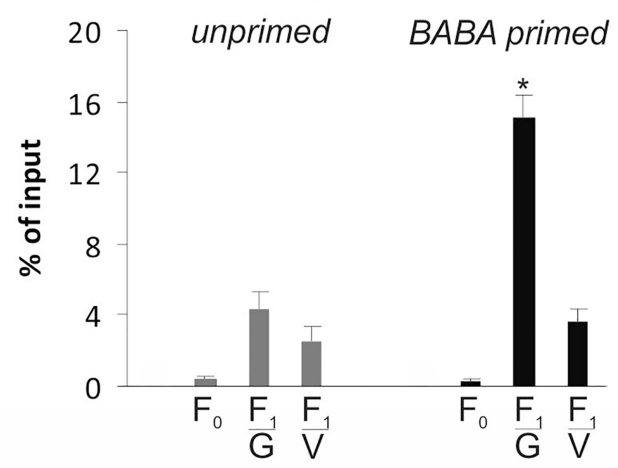

H3K9me2

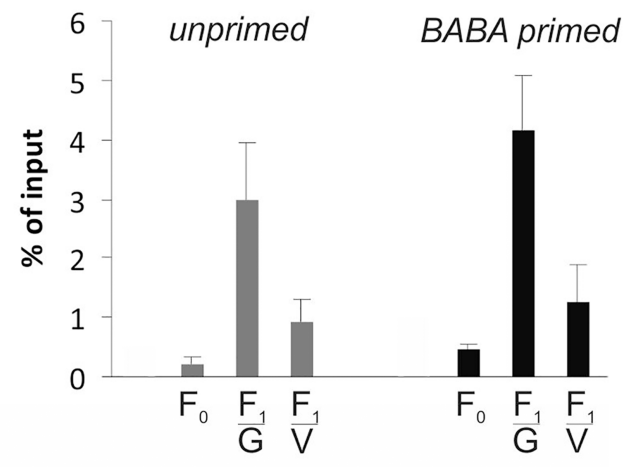

FIGURE 7 | Epigenetic marks on SA-dependent genes in response to BABA-priming. Distribution levels of H3K4me2 and H3K9me3 on the gene body region of WRKY1 (A), PR1 (B) and PR2 (C) at the stage before the second challenge. ChIP-qPCR analyses were performed after 5 mM BABA (BABA-primed) or water treatment (unprimed), in the parental line $\left(F_{0}\right)$ and its descendants $\left(F_{1}\right)$ derived from tubers $\left(F_{1} / v\right)$ or seeds $\left(F_{1} / G\right)$. Each experiment was repeated three times and the data are presented as percentages of input DNA. Asterisks indicate values that differ significantly from unprimed (water treated) potato leaves at $P<0.05\left(^{*}\right)$.

an enhanced capacity to mobilize faster and stronger defense responses to $P$. infestans within the same $\left(\mathrm{F}_{0}\right)$ and in the next vegetative and generative progeny of primed plants $\left(\mathrm{F}_{1}\right)$ when compared to unprimed parental plants and their progeny. It was observed that primed potato plants further changed their response pattern to regulate a network of SA-dependent gene 
expression differing from that involved in unprimed plants. The state of an intergenerational resistance to pathogen correlated with the transcriptional memory of gene expression, which we observed, encouraged us to investigate whether a transient plant exposure to BABA leads to chromatin modifications that could be maintained through mitotic or meiotic cell divisions and thereby preserve a particular expression pattern of stress response genes.

We identified specific histone $\mathrm{H} 3$ modifications that are known to be potentially associated with transcriptional reprogramming of gene expression toward the retention of information on previous stress exposure. BABA-primed potato exhibited the biphasic changes in gene expression for the $\mathrm{H3}, \mathrm{H} 4$, and chromatin assembly factor 1 (CAF1), being an $\mathrm{H} 3-\mathrm{H} 4$ histone chaperone. The first upregulation of these genes was found immediately after BABA treatment, while the other appeared upon the challenge inoculation.

Recently it was found in Arabidopsis leaves, as a non-dividing cell system, that the histone chaperone CAF-1 is required to establish a repressed chromatin state at defense genes. The CAF-1 mutant (faciata 2 mutant) defective in CAF-1 activity showed SA and BABA-induced activation of defense genes comparable to a constitutive priming response (Mozgová et al., 2015).

There is a good reason to believe that the biphasic changes in gene expression for CAF1 observed by us in primed potato leaves might be associated with preventing overexpression of stressresponsive genes when the first stress was over. Nevertheless, more knowledge is needed on how CAF-1 deposits H3$\mathrm{H} 4$ to provide a greater understanding of the mechanism for the maintenance and inheritance of histone modifications either through nucleosome recycling or copying of a proper modification into the newly incorporated histone (Mattiroli et al., 2017).

Based on the histone lysine acetylation results an antagonistic interaction between HDAs and HATs gene expressions was observed in BABA-primed potato leaves. This outcome is in agreement with the proposal that both HATs and HDACs work in a global, untargeted fashion, and broadly affect the plant genome in two different manners (Shahbazian and Grunstein, 2007). Moreover, the obtained evidence showed that BABA did not activate HATs until the plants were stimulated by the second stress stimulus. Thus histone acetylation increased mainly after the triggering stress and it was related to the augmented expression of the PR1 and PR2 genes.

Also, the finding of Luna et al. (2014) documented that acetylation was not essential for long-lasting BABA priming of SA-inducible genes within one Arabidopsis generation. Nevertheless, this does not preclude the supposition that H3K9 acetylation may perform an independent role in targeting potential genes in the priming state (Jaskiewicz et al., 2011; Luna et al., 2012). Generally, histone acetylation by HATs is associated with transcriptional activation, while histone deacetylation by HDACs is considered to be transcriptional inhibition tuned with the de-repression of SA-based defenses (Choi et al., 2012). Despite the above, HDA6 and HDA19 may be associated with transcriptional activation of the JA/ET-induced $P R$ s genes (Zhou, 2005; Wu et al., 2008). Moreover, it is hypothesized that HDA6 is necessary for erasing histones, before RNA Polymerases (Pol IV) and methyltransferases may be involved in DNA methylation in order to provide locus-directed chromatin silencing (Liu et al., 2010; Blevins et al., 2014).

In our study, the transcript profiles of $H D A C$ showed an enhanced expression upon BABA treatment followed by a decrease, but they maintained an elevated level under the triggering stress in comparison to unprimed-inoculated leaves. As it was hypothesized in Arabidopsis, HDA19 by modifying chromatin to a repressive state could prevent redundant overactivation of defense responses in the absence of the pathogen or, when needed, prepare an efficient expression without overestimation of defense responses under pathogen attack (Choi et al., 2012).

Next, among the other histone modifications, we focused on lysine methylation, being a more stable modification than acetylation, with the function in affecting gene expression as well (Morgunkova and Barlev, 2006). In order to assess whether histone $\mathrm{H} 3$ methylation mediated by methyltransferases TrxG or SUVH4 could play a role in the regulation of BABA priming response in potato, possible alternations between their transcript profiles were analyzed. The data revealed that the $\operatorname{Tr} x G$ gene expression was early and strongly up-regulated upon BABA supply when compared to the unprimed potato. Interestingly, afterward the level of mRNA transcript accumulation for $\operatorname{Tr} x G$ gradually diminished also after challenge inoculation, although $\operatorname{TrxG}$ transcription still remained higher when compared to unprimed-inoculated leaves.

Experimental evidence confirmed that TrxG proteins as chromatin regulators are involved in switching genes on and keeping them active (Schuettengruber et al., 2011, 2017). This could mean that the post-translational $\mathrm{H} 3 \mathrm{~K} 4 \mathrm{di}-$ and trimethylation managed by the TrxG protein might serve as a molecular starter for a memory controlling subsequent priming response (Ding et al., 2012; Fromm and Avramova, 2014). In particular tri-methylation of lysine 4 on histone $3(\mathrm{H} 3 \mathrm{~K} 4 \mathrm{me} 3)$ is a hallmark of active genes in plant and animal systems; however, in plants di-methylation is also implicated in global gene activation (Lusser, 2002; Po-Wen et al., 2013).

As documented in other reports, SUVH4 belonging to the $\mathrm{PcG}$ group represses thousands of stress-regulated genes by $\mathrm{H} 3 \mathrm{~K} 27 \mathrm{me} 3$ or $\mathrm{H} 3 \mathrm{~K} 9 \mathrm{me} 2$ for heritable heterochromatin assembly (Kleinmanns et al., 2017). We also found in our analyses that SUVH4 presented an antagonistic tendency of transcription compared with the $\operatorname{Tr} x G$ gene expression after BABA exposure.

The JMJ706 protein has been suggested to function as a histone demethylase and to specifically reverse di- and trimethylation of $\mathrm{H} 3 \mathrm{~K} 9$, thus disassembling heterochromatin from the repressive state (Sun and Zhou, 2008; Qian et al., 2015). The presented data showed that JMJ706 transcription increased immediately after the recognition of the BABA signal, while also its transcription levels were much higher after inoculation with $P$. infestans in the offspring plants $\left(\mathrm{F}_{1}\right)$. These results correlated 
with an enhanced accumulation of $\mathrm{H} 3 \mathrm{~K} 9 \mathrm{me} 2$ and $\mathrm{H} 3 \mathrm{~K} 4 \mathrm{me} 2$ on the SA-dependent genes.

Interestingly, it was documented that $\mathrm{H} 3 \mathrm{~K} 4 \mathrm{me} 3$ can also act as a docking site for $\mathrm{H} 3 \mathrm{~K} 9 \mathrm{me} 2$ demethylases (Horton et al., 2010). Accumulated data revealed that epigenetic marks cannot be analyzed alone, but rather in combination with various histone modifications and their time-dependent mutual relationships define the open/close chromatin structure and create transcriptional competence to store information in the form of transcriptional memory of trainable genes (Avramova, 2015; de la Paz Sanchez et al., 2015; Pu and Sung, 2015; Fletcher, 2017).

Indeed, ChIP with RT-qPCR analyses in primed potato leaves revealed basic time-dependent differences in relation to the three analyzed histone methylation marks (H3K4me2, $\mathrm{H} 3 \mathrm{~K} 27 \mathrm{me} 3$ and $\mathrm{H} 3 \mathrm{~K} 9 \mathrm{me} 2$ ) on the gene body region of NPR 1 and SNI1, which encode opposite key regulators of plant immunity. Another finding of interest showed that BABA induced an epigenetic mechanism, in which the chromatin state switchable by transcriptional activation or repression of the NPR1 and SNI1 genes probably yielded input for reprogramming of the SA-dependent genes and contributed to the stress imprinting.

It is in line with other published results, indicating that mutually antagonistic bivalent histone marks, H3K4me2/3 and H3K27me3, have to be tightly balanced even at the same locus (Du et al., 2013; Trindade et al., 2017).

Our data indicate that $\mathrm{H} 3 \mathrm{~K} 4 \mathrm{me} 2 / \mathrm{TrxG}$ was probably required for the initial NPR1-dependent immune triggering, while $\mathrm{H} 3 \mathrm{~K} 27 \mathrm{me} 3 / \mathrm{SUVH} 4$ was needed rather for the establishment and maintenance of the histone methylation pattern, required to imprint the information for future use.

To date, despite many significant findings on the posttranslational modifications of NPR1, summarized in a review paper by Pajerowska-Mukhtar et al. (2013), experimental data on the possibility of an NPR1 interaction with chromatin remodeling proteins and DNA methylation remain poorly understood. It was documented that the Elongator complex subunit2 (ELP2) exhibiting HAT activity is required to regulate both NPR1 and its target defense genes in Arabidopsis (Wang et al., 2013).

In turn, SNI1 as a negative regulator of SAR was apparently needed to dampen the BABA primed signal, transduced by the $N P R 1$ into transient $P R-1$ and $P R-2$ gene expression and engaged in the time-dependent regulation of the transcriptional potential distribution to maintain a positive cost-balance after priming to a second distant triggering stress by $P$. infestans.

When looking for a clarification of the epigenetic mechanism, by which SNI1 modifies transcription, it was postulated that the transcriptional repression activity could be achieved both by histone modification or chromatin remodeling, with SNI1 possibly forming a scaffold to interact with the transcription modulator (Cowell, 1994; Gaston and Jayaraman, 2003; Mosher et al., 2006). However, since then apart from SNI1 much more has been learned concerning the regulation of SNC1 (Suppressor of NPR1, Constitutive) expression by chromatin remodeling complexes, including ATX7 and SNC1-mediated $R$ gene immunity (Xia et al., 2013; Johnson et al., 2015) and other chromatin remodelers (Zou et al., 2017). Unfortunately, both
SNC1 and SNI1 downregulating NPR1 are encoded by various gene structures and they impair host resistance through different molecular mechanisms (Maldonado et al., 2014).

In plants, their capacity to reprogram gene expression associated with the transcriptional memory of stress involves heritable histone modifications seen as epigenetic marks (Avramova, 2015). The increased presence of H3K4me2/3 or/and $\mathrm{H} 3 \mathrm{~K} 9 \mathrm{ac}$ inversely to the transcript accumulation was found at memory genes in response to biotic stresses (Jaskiewicz et al., 2011; Ramírez et al., 2013; Martínez-Aguilar et al., 2016). We investigated an enhanced occupancy of H3K4me2 tag on the gene body of $W R K Y 1, P R 1$, and $P R 2$ concomitant with transcript downregulation detected in leaves of primed potato and its descendants before the triggering stress. Nevertheless, how this epigenetic mark might promote the state of potato ability to mount an effective defense against a later virulent pathogen attack remains largely unanswered. An interesting hypothesis was postulated in mammalian research, suggesting that $\mathrm{H} 3 \mathrm{~K} 4 \mathrm{me} 3$ antagonizes de novo DNA methylation at some genomic loci by blocking the Dnmt3 DNA methyltransferase (Otani et al., 2009).

The research carried out to identify the long-lasting memory revealed the importance of $\mathrm{H} 3 \mathrm{~K} 9 / \mathrm{SUVH} 4$ methylation in keeping repressive modification at specific genomic sites related to priming to subsequent modulating effective immune responses at a minimal fitness cost (Martinez-Medina et al., 2016). In our experiment, the BABA priming induced a temporary increase in the $\mathrm{H} 3 \mathrm{~K} 9 \mathrm{me} 2$ level on stress-responsive genes during transcriptionally inactive states before the second stress. Such changes in the deposition of histone marks, noted mainly in $\mathrm{F}_{1}$ line genes derived from BABA-primed plants, might work as the heritable storage of information after priming.

Other experimental evidence documented that $\mathrm{H} 3 \mathrm{~K} 9$ methyltransferase by the KYP protein (SUVH4/KRYPTONITE) was necessary for long-lasting BABA-induced resistance in Arabidopsis (Luna et al., 2014). Interestingly, it was stated that $\mathrm{H} 3 \mathrm{~K} 9 \mathrm{me} 2$ is necessary for DNA methylation in the $\mathrm{CpNpG}$ sequence context mediated by CHROMOMETHYLASE 3 in Arabidopsis (Jackson et al., 2002; Saze and Kakutani, 2011; Du et al., 2012). A differentially methylated DNA region is usually much more stable compared to the dynamic histone changes and could be transgenerationally propagated in an intact form through mitosis and meiosis.

In order to find a functional link between various epigenetic modifications, simultaneously we examined the DNA methylation and demethylation status in potato plants contributing to BABA-primed changes associated with the transcriptional memory to improve resistance against $P$. infestans (paper under review). The same experimental design revealed that transcriptional priming of some SA-dependent genes (NPR1, WRKY1, and PR1) was not directly due to DNA methylation. Among other interesting issues, the vegetative and generative offspring of primed plants carrying a less methylated $R 3 a$ promoter showed an earlier and higher transcription of $R 3 a$, correlated with an enhanced intergenerational resistance to $P$. infestans, when compared to the inoculated progeny of unprimed potato. 


\section{CONCLUSION}

The offspring of BABA-primed potato, subjected to the samegeneration priming, maintained an enhanced resistance to $P$. infestans over one stress-free generation. The obtained data revealed that a time-dependent and opposite combination of different histone modifications on the NPR1 and SNI1 gene loci via histone methyltransferases (TrxG / SUVH4) and demethylase (JMJ706), seems to be essential for a successful fixation of the priming and intergenerational resistance to $P$. infestans. BABA-triggered switchable chromatin states with an opposite transcription on the NPR1 and SNI1 genes might reprogram stress response $P R 1$ and $P R 2$ genes and confer competence to store information in the form of transcriptional memory associated with the $\mathrm{H} 3 \mathrm{~K} 4 \mathrm{me} 2$ epigenetic mark. It is proposed that the $\mathrm{H} 3 \mathrm{~K} 9 \mathrm{me} 2$ methylation pattern may act in potato as part of such an immune sensory system closely linked to other epigenetic changes, such as DNA methylation. In turn, histone acetylation had not been essential for the establishment of the priming state until potato plants were challenged by the second stress, when a rapid and boosted $P R$ s trainable gene expression probably required HAT activity both in $\mathrm{F}_{0}$ and $\mathrm{F}_{1}$ progeny.

\section{AUTHOR CONTRIBUTIONS}

JF-W, MA-J, and JD planned and designed the research. BM and DK performed the experiments, and collected and analyzed the data. JF-W wrote the manuscript.

\section{FUNDING}

This work was supported by the grant of the National Science Centre; project NCN No. 2013/11/B/NZ9/01903.

\section{REFERENCES}

Alvarez-Venegas, R., and Avramova, Z. (2005). Methylation patterns of histone H3 Lys 4, Lys 9 and Lys 27 in transcriptionally active and inactive Arabidopsis genes and in atx1 mutants. Nucleic Acids Res. 33, 5199-5207. doi: 10.1093/nar/gki830

Audergon, P. N. C. B., Catania, S., Kagansky, A., Tong, P., Shukla, M., Pidoux, A. L., et al. (2015). Restricted epigenetic inheritance of H3K9 methylation. Science 348, 132-135. doi: 10.1126/science. 1260638

Avramova, Z. (2015). Transcriptional 'memory' of a stress: transient chromatin and memory (epigenetic) marks at stress-response genes. Plant J. 83, 149-159. doi: $10.1111 /$ tpj.12832

Bernatavichute, Y. V., Zhang, X., Cokus, S., Pellegrini, M., and Jacobsen, S. E. (2008). Genome-wide association of histone H3 lysine nine methylation with CHG DNA methylation in Arabidopsis thaliana. PLoS One 3:e3156. doi: 10. 1371/journal.pone.0003156

Blevins, T., Pontvianne, F., Cocklin, R., Podicheti, R., Chandrasekhara, C., Yerneni, S., et al. (2014). A two-step process for epigenetic inheritance in Arabidopsis. Mol. Cell 54, 30-42. doi: 10.1016/j.molcel.2014.02.019

Boycheva, I., Vassileva, V., and Iantcheva, A. (2014). Histone acetyltransferases in plant development and plasticity. Curr. Genom. 15, 28-37. doi: 10.2174/ 138920291501140306112742

Chen, X., Hu, Y., and Zhou, D.-X. (2011). Epigenetic gene regulation by plant Jumonji group of histone demethylase. Biochim. Biophys. Acta BBA - Gene Regul. Mech. 1809, 421-426. doi: 10.1016/j.bbagrm.2011.03.004

\section{SUPPLEMENTARY MATERIAL}

The Supplementary Material for this article can be found online at: https://www.frontiersin.org/articles/10.3389/fpls.2018.01228/ full\#supplementary-material

FIGURE S1 | Transcriptional activity of CAF-1 in primed potato progeny derived from tubers (A) and seeds (B) after inoculation with $P$. infestans. Analyses were performed at 1-48 hpi after challenge inoculation. Light columns refer to unprimed while dark columns - to primed plants subjected to inoculation. Values represent means of data $\pm S D$ of at least three independent experiments. Asterisks indicate values that differ significantly from unprimed and $P$. infestans inoculated potato leaves at $P<0.05\left(^{*}\right)$, respectively.

FIGURE S2 | Transcription patters of histone acetylation (HAT) and deacetylation $(H D A C)$ in primed potato progeny derived from tubers $\mathbf{( A )}$ and seeds $\mathbf{B}$ ) after inoculation with $P$. infestans. Analyses were performed at 1-48 hpi after challenge inoculation. Light columns refer to unprimed, while dark columns - to primed plants subjected to inoculation. Values represent means of data $\pm \mathrm{SD}$ of at least three independent experiments. Asterisks indicate values that differ significantly from unprimed and $P$. infestans inoculated potato leaves at $P<0.05\left(^{*}\right)$, respectively.

FIGURE S3 | Transcript levels of genes modifying histone methylation - TrxG (A), SUVH4 (B), and demethylation JMJ706 (C) in primed potato progeny derived from tubers after inoculation with $P$. infestans. Analyses were performed at 1-48 hpi after challenge inoculation. Light columns refer to unprimed, while dark columns - to primed plants subjected to inoculation. Values represent means of data \pm SD of at least three independent experiments. Asterisks indicate values that differ significantly from unprimed and $P$. infestans inoculated potato leaves at $P<0.05\left(^{*}\right)$, respectively.

FIGURE S4 | Transcript levels of genes modifying histone methylation - TrxG (A), SUVH4 (B), and demethylation JMJ706 (C) in primed potato progeny derived from seeds after inoculation with $P$. infestans. Analyses were performed at 1-48 hpi after challenge inoculation. Light columns refer to unprimed, while dark columns - to primed plants subjected to inoculation. Values represent means of data \pm SD of at least three independent experiments. Asterisks indicate values that differ significantly from unprimed and $P$. infestans inoculated potato leaves at $P<0.05\left(^{*}\right)$, respectively.

TABLE S1 | List of designed primers.

Choi, S.-M., Song, H.-R., Han, S.-K., Han, M., Kim, C.-Y., Park, J., et al. (2012). HDA19 is required for the repression of salicylic acid biosynthesis and salicylic acid-mediated defense responses in Arabidopsis: repression of SA-mediated defense by HDA19. Plant J. 71, 135-146. doi: 10.1111/j.1365-313X.2012.04 977.x

Conrath, U. (2011). Molecular aspects of defence priming. Trends Plant Sci. 16, 524-531. doi: 10.1016/j.tplants.2011.06.004

Cowell, I. G. (1994). Repression versus activation in the control of gene transcription. Trends Biochem. Sci. 19, 38-42. doi: 10.1016/0968-0004(94) 90172-4

Crespo-Salvador, Ó, Escamilla-Aguilar, M., López-Cruz, J., López-Rodas, G., and González-Bosch, C. (2018). Determination of histone epigenetic marks in Arabidopsis and tomato genes in the early response to Botrytis cinerea. Plant Cell Rep. 37, 153-166. doi: 10.1007/s00299-017-2218-9

de la Paz Sanchez, M., Aceves-García, P., Petrone, E., Steckenborn, S., VegaLeón, R., Álvarez-Buylla, E. R., et al. (2015). The impact of polycomb group $(\mathrm{PcG})$ and trithorax group (TrxG) epigenetic factors in plant plasticity. New Phytol. 208, 684-694. doi: 10.1111/nph.13486

Derkacheva, M., and Hennig, L. (2014). Variations on a theme: polycomb group proteins in plants. J. Exp. Bot. 65, 2769-2784. doi: 10.1093/jxb/ert410

Ding, B., Bellizzi, M. R., Ning, Y., Meyers, B. C., and Wang, G.-L. (2012). HDT701, a histone $\mathrm{H} 4$ deacetylase, negatively regulates plant innate immunity by modulating histone $\mathrm{H} 4$ acetylation of defense-related genes in rice. Plant Cell 24, 3783-3794. doi: 10.1105/tpc.112.101972 
Dong, X., and Weng, Z. (2013). The correlation between histone modifications and gene expression. Epigenomics 5, 113-116. doi: 10.2217/epi.13.13

Du, J., Zhong, X., Bernatavichute, Y. V., Stroud, H., Feng, S., Caro, E., et al. (2012). Dual binding of chromomethylase domains to H3K9me2containing nucleosomes directs DNA methylation in plants. Cell 151, 167-180. doi: 10.1016/j.cell.2012.07.034

Du, Z., Li, H., Wei, Q., Zhao, X., Wang, C., Zhu, Q., et al. (2013). Genomewide analysis of histone modifications: H3K4me2, H3K4me3, H3K9ac, and H3K27ac in Oryza sativa L. Japonica. Mol. Plant 6, 1463-1472. doi: 10.1093/mp/ sst018

Fletcher, J. C. (2017). State of the Art: TrxG factor regulation of post-embryonic plant development. Front. Plant Sci. 8:1925. doi: 10.3389/fpls.2017.01925

Floryszak-Wieczorek, J., Arasimowicz-Jelonek, M., and Abramowski, D. (2015). BABA-primed defense responses to Phytophthora infestans in the next vegetative progeny of potato. Front. Plant. Sci. 6:844. doi: 10.3389/fpls.2015. 00844

Fromm, M., and Avramova, Z. (2014). ATX1/AtCOMPASS and the H3K4me3 marks: how do they activate Arabidopsis genes? Curr. Opin. Plant Biol. 21, 75-82. doi: 10.1016/j.pbi.2014.07.004

Gaston, K., and Jayaraman, P.-S. (2003). Transcriptional repression in eukaryotes: repressors and repression mechanisms. Cell. Mol. Life Sci CMLS 60, 721-741. doi: 10.1007/s00018-003-2260-3

Haring, M., Offermann, S., Danker, T., Horst, I., Peterhansel, C., and Stam, M. (2007). Chromatin immunoprecipitation: optimization, quantitative analysis and data normalization. Plant Methods 3:11. doi: 10.1186/1746-4811-3-11

Horton, J. R., Upadhyay, A. K., Qi, H. H., Zhang, X., Shi, Y., and Cheng, X. (2010). Enzymatic and structural insights for substrate specificity of a family of jumonji histone lysine demethylases. Nat. Struct. Mol. Biol. 17, 38-43. doi: 10.1038/nsmb.1753

Jackson, J. P., Lindroth, A. M., Cao, X., and Jacobsen, S. E. (2002). Control of CPNpG DNA methylation by the KRYPTONITE histone H3 methyltransferase. Nature 416, 556-560. doi: 10.1038/nature731

James, C. (1971). A Manual of Assessment Keys for Plant Diseases, Vol. 51. St. Paul, MN: American Phytopathological Society.

Jaskiewicz, M., Peterhansel, C., and Conrath, U. (2011). Detection of histone modifications in plant leaves. J. Vis. Exp. e3096. doi: 10.3791/3096

Johnson, K. C. M., Xia, S., Feng, X., and Li, X. (2015). The chromatin remodeler SPLAYED negatively regulates SNC1-mediated immunity. Plant Cell Physiol. 56, 1616-1623. doi: 10.1093/pcp/pcv087

Kim, D.-H., and Sung, S. (2014). Genetic and epigenetic mechanisms underlying vernalization. Arab. Book 12:e0171. doi: 10.1199/tab.0171

Kim, J.-M., To, T. K., Ishida, J., Matsui, A., Kimura, H., and Seki, M. (2012). Transition of chromatin status during the process of recovery from drought stress in Arabidopsis thaliana. Plant Cell Physiol. 53, 847-856. doi: 10.1093/pcp/ pcs053

Kleinmanns, J. A., Schatlowski, N., Heckmann, D., and Schubert, D. (2017). BLISTER regulates polycomb-target genes, represses stress-regulated genes and promotes stress responses in Arabidopsis thaliana. Front. Plant Sci. 8:1530. doi: 10.3389/fpls.2017.01530

Kleinmanns, J. A., and Schubert, D. (2014). Polycomb and Trithorax group protein-mediated control of stress responses in plants. Biol. Chem. 395, 12911300. doi: 10.1515/hsz-2014-0197

Köhler, C., and Hennig, L. (2010). Regulation of cell identity by plant Polycomb and trithorax group proteins. Curr. Opin. Genet. Dev. 20, 541-547. doi: 10.1016/ j.gde.2010.04.015

Köhler, C., Wolff, P., and Spillane, C. (2012). Epigenetic mechanisms underlying genomic imprinting in plants. Annu. Rev. Plant Biol. 63, 331-352. doi: 10.1146/ annurev-arplant-042811-105514

Komar, D. N., Mouriz, A., Jarillo, J. A., and Pieiro, M. (2016). Chromatin Immunoprecipitation assay for the identification of Arabidopsis protein-DNA interactions in vivo. J. Vis. Exp. 14:e53422. doi: 10.3791/53422

Lämke, J., and Bäurle, I. (2017). Epigenetic and chromatin-based mechanisms in environmental stress adaptation and stress memory in plants. Genome Biol. 18:124. doi: 10.1186/s13059-017-1263-6

Li, J., Brader, G., and Palva, E. T. (2004). The WRKY70 transcription factor: a node of convergence for jasmonate-mediated and salicylate-mediated signals in plant defense. Plant Cell 16, 319-331. doi: 10.1105/tpc.016980
Liu, C., Lu, F., Cui, X., and Cao, X. (2010). Histone methylation in higher plants. Annu. Rev. Plant Biol. 61, 395-420. doi: 10.1146/annurev.arplant.043008. 091939

López, A., Ramírez, V., García-Andrade, J., Flors, V., and Vera, P. (2011). The RNA silencing enzyme RNA polymerase $\mathrm{V}$ Is required for plant immunity. PLoS Genet. 7:e1002434. doi: 10.1371/journal.pgen.1002434

Luna, E., Bruce, T. J. A., Roberts, M. R., Flors, V., and Ton, J. (2012). Next-generation systemic acquired resistance. Plant Physiol. 158, 844-853. doi: $10.1104 /$ pp. 111.187468

Luna, E., López, A., Kooiman, J., and Ton, J. (2014). Role of NPR1 and KYP in long-lasting induced resistance by $\beta$-aminobutyric acid. Front. Plant Sci. 5:184. doi: $10.3389 /$ fpls.2014.00184

Lusser, A. (2002). Acetylated, methylated, remodeled: chromatin states for gene regulation. Curr. Opin. Plant Biol. 5, 437-443. doi: 10.1016/S1369-5266(02) 00287-X

Maldonado, A., Youssef, R., McDonald, M., Brewer, E., Beard, H., and Matthews, B. (2014). Modification of the expression of two NPR1 suppressors, SNC1 and SNI1, in soybean confers partial resistance to the soybean cyst nematode, Heterodera glycines. Funct. Plant Biol. 41:714. doi: 10.1071/FP13323

Martínez-Aguilar, K., Ramírez-Carrasco, G., Hernández-Chávez, J. L., Barraza, A., and Alvarez-Venegas, R. (2016). Use of BABA and INA as activators of a primed state in the common bean (Phaseolus vulgaris L.). Front. Plant Sci. 7:653. doi: $10.3389 /$ fpls.2016.00653

Martinez-Medina, A., Flors, V., Heil, M., Mauch-Mani, B., Pieterse, C. M., Pozo, M. J., et al. (2016). Recognizing plant defense priming. Trends Plant Sci. 21, 818-822. doi: 10.1016/j.tplants.2016.07.009

Mattiroli, F., Gu, Y., Balsbaugh, J. L., Ahn, N. G., and Luger, K. (2017). The Cac2 subunit is essential for productive histone binding and nucleosome assembly in CAF-1. Sci. Rep. 7:46274. doi: 10.1038/srep46274

Mauch-Mani, B., Baccelli, I., Luna, E., and Flors, V. (2017). Defense priming: an adaptive part of induced resistance. Annu. Rev. Plant Biol. 68, 485-512. doi: 10.1146/annurev-arplant-042916-041132

Morgunkova, A., and Barlev, N. A. (2006). Lysine methylation goes global. Cell Cycle 5, 1308-1312. doi: 10.4161/cc.5.12.2820

Mosher, R. A., Durrant, W. E., Wang, D., Song, J., Dong, J. (2006). A comprehensive structure-function analysis of Arabidopsis SNI1 defines essential regions and transcriptional repressor activity. Plant Cell 18, 17501765. doi: $10.1105 /$ tpc. 105.039677

Mozgová, I., Wildhaber, T., Liu, Q., Abou-Mansour, E., L'Haridon, F., Métraux, J.P., et al. (2015). Chromatin assembly factor CAF-1 represses priming of plant defence response genes. Nat. Plants 1:15127. doi: 10.1038/nplants.2015.127

Otani, J., Nankumo, T., Arita, K., Inamoto, S., Ariyoshi, M., and Shirakawa, M. (2009). Structural basis for recognition of H3K4 methylation status by the DNA methyltransferase 3A ATRX-DNMT3-DNMT3L domain. EMBO Rep. 10, 1235-1241. doi: 10.1038/embor.2009.218

Pajerowska-Mukhtar, K. M., Emerine, D. K., and Mukhtar, M. S. (2013). Tell me more: roles of NPRs in plant immunity. Trends Plant Sci. 18, 402-411. doi: 10.1016/j.tplants.2013.04.004

Pfaffl, M. W. (2001). A new mathematical model for relative quantification in real-time RT-PCR. Nucleic Acids Res. 29, e45. doi: 10.1093/nar/ 29.9.e45

Pieterse, C. M., and Van Loon, L. (2004). NPR1: the spider in the web of induced resistance signaling pathways. Curr. Opin. Plant Biol. 7, 456-464. doi: 10.1016/ j.pbi.2004.05.006

Po-Wen, C., Singh, P., and Zimmerli, L. (2013). Priming of the Arabidopsis patterntriggered immunity response upon infection by necrotrophic Pectobacterium carotovorum bacteria: priming of Arabidopsis pattern-triggered immunity. Mol. Plant Pathol. 14, 58-70. doi: 10.1111/j.1364-3703.2012.00827.x

$\mathrm{Pu}$, L., and Sung, Z. R. (2015). PcG and trxG in plants - friends or foes. Trends Genet. 31, 252-262. doi: 10.1016/j.tig.2015.03.004

Qian, S., Wang, Y., Ma, H., and Zhang, L. (2015). Expansion and functional divergence of jumonji C-containing histone demethylases: significance of duplications in ancestral angiosperms and vertebrates. Plant Physiol. 168, 1321-1337. doi: 10.1104/pp.15.00520

Ramírez, V., López, A., Mauch-Mani, B., Gil, M. J., and Vera, P. (2013). An extracellular subtilase switch for immune priming in Arabidopsis. PLoS Pathog. 9:e1003445. doi: 10.1371/journal.ppat.1003445 
Saubeau, G., Perrin, F., Marnet, N., Andrivon, D., and Val, F. (2016). Hormone signalling pathways are differentially involved in quantitative resistance of potato to Phytophthora infestans. Plant Pathol. 65, 342-352. doi: 10.1111/ppa. 12420

Saze, H., and Kakutani, T. (2011). Differentiation of epigenetic modifications between transposons and genes. Curr. Opin. Plant Biol. 14, 81-87. doi: 10.1016/ j.pbi.2010.08.017

Schuettengruber, B., Bourbon, H.-M., Di Croce, L., and Cavalli, G. (2017). Genome regulation by polycomb and trithorax: 70 years and counting. Cell 171, 34-57. doi: 10.1016/j.cell.2017.08.002

Schuettengruber, B., Martinez, A.-M., Iovino, N., and Cavalli, G. (2011). Trithorax group proteins: switching genes on and keeping them active. Nat. Rev. Mol. Cell Biol. 12, 799-814. doi: 10.1038/nrm3230

Shahbazian, M. D., and Grunstein, M. (2007). Functions of site-specific histone acetylation and deacetylation. Annu. Rev. Biochem. 76, 75-100. doi: 10.1146/ annurev.biochem.76.052705.162114

Shen, Y., Conde e Silva, N., Audonnet, L., Servet, C., Wei, W., and Zhou, D.-X. (2014). Over-expression of histone H3K4 demethylase gene JMJ15 enhances salt tolerance in Arabidopsis. Front. Plant Sci. 5:290. doi: 10.3389/fpls.2014.00290

Shi, Y., Lan, F., Matson, C., Mulligan, P., Whetstine, J. R., Cole, P. A., et al. (2004). Histone demethylation mediated by the nuclear amine oxidase homolog LSD1. Cell 119, 941-953. doi: 10.1016/j.cell.2004.12.012

Slaughter, A., Daniel, X., Flors, V., Luna, E., Hohn, B., and Mauch-Mani, B. (2012). Descendants of primed Arabidopsis plants exhibit resistance to biotic stress. Plant Physiol. 158, 835-843. doi: 10.1104/pp.111.191593

Sun, Q., and Zhou, D.-X. (2008). Rice jmjC domain-containing gene JMJ706 encodes H3K9 demethylase required for floral organ development. Proc. Natl. Acad. Sci. U.S.A. 105, 13679-13684. doi: 10.1073/pnas.0805901105

Tichopad, A., Didier, A., and Pfaffl, M. W. (2004). Inhibition of real-time RT-PCR quantification due to tissue-specific contaminants. Mol. Cell. Probes 18, 45-50. doi: 10.1016/j.mcp.2003.09.001

Trindade, I., Schubert, D., and Gaudin, V. (2017). "Epigenetic regulation of phase transitions in Arabidopsis thaliana," in Plant Epigenetics, eds N. Rajewsky, S. Jurga, and J. Barciszewski (Cham: Springer International Publishing), 359-383. doi: 10.1007/978-3-319-55520-1_18

Wang, Y., An, C., Zhang, X., Yao, J., Zhang, Y., Sun, Y., et al. (2013). The Arabidopsis elongator complex Subunit2 epigenetically regulates plant immune responses. Plant Cell 25, 762-776. doi: 10.1105/tpc.113.109116

Wilkinson, S. W., Pastor, V., Paplauskas, S., Pétriacq, P., and Luna, E. (2018). Longlasting $\beta$-aminobutyric acid-induced resistance protects tomato fruit against Botrytis cinerea. Plant Pathol. 67, 30-41. doi: 10.1111/ppa.12725

Wilson, U. E., and Coffey, M. D. (1980). Cytological evaluation of general resistance to Phytophthora infestans in potato foliage. Ann. Bot. 45, 81-90.

Worrall, D., Holroyd, G. H., Moore, J. P., Glowacz, M., Croft, P., Taylor, J. E., et al. (2012). Treating seeds with activators of plant defence generates long-lasting priming of resistance to pests and pathogens. New Phytol. 193, 770-778. doi: 10.1111/j.1469-8137.2011.03 987.x

Wu, K., Zhang, L., Zhou, C., Yu, C.-W., and Chaikam, V. (2008). HDA6 is required for jasmonate response, senescence and flowering in Arabidopsis. J. Exp. Bot. 59, 225-234. doi: 10.1093/jxb/erm300

Xia, S., Cheng, Y. T., Huang, S., Win, J., Soards, A., Jinn, T.-L., et al. (2013). Regulation of transcription of nucleotide-binding leucine-rich repeat-encoding genes SNC1 and RPP4 via H3K4 Trimethylation. Plant Physiol. 162, 1694-1705. doi: $10.1104 /$ pp.113.214551

Xiao, J., Lee, U.-S., and Wagner, D. (2016). Tug of war: adding and removing histone lysine methylation in Arabidopsis. Curr. Opin. Plant Biol. 34, 41-53. doi: 10.1016/j.pbi.2016.08.002

Xu, L., Zhao, Z., Dong, A., Soubigou-Taconnat, L., Renou, J.-P., Steinmetz, A., et al. (2008). Di- and Tri- but not monomethylation on histone H3 Lysine 36 marks active transcription of genes involved in flowering time regulation and other processes in Arabidopsis thaliana. Mol. Cell. Biol. 28, 1348-1360. doi: 10.1128/MCB.01607-07

Zhang, X. (2008). The epigenetic landscape of plants. Science 320, 489-492. doi: $10.1126 /$ science.1153996

Zhang, X., Bernatavichute, Y. V., Cokus, S., Pellegrini, M., and Jacobsen, S. E. (2009). Genome-wide analysis of mono-, di- and trimethylation of histone $\mathrm{H} 3$ lysine 4 in Arabidopsis thaliana. Genome Biol. 10:R62. doi: 10.1186/gb-2009-106-r62

Zhao, S., and Fernald, R. D. (2005). Comprehensive algorithm for quantitative realtime polymerase chain reaction. J. Comput. Biol. J. Comput. Mol. Cell Biol. 12, 1047-1064. doi: 10.1089/cmb.2005.12.1047

Zhou, C. (2005). HISTONE DEACETYLASE19 is involved in jasmonic acid and ethylene signaling of pathogen response in Arabidopsis. Plant Cell Online 17, 1196-1204. doi: 10.1105/tpc.104.028514

Zou, B., Sun, Q., Zhang, W., Ding, Y., Yang, D.-L., Shi, Z., et al. (2017). The Arabidopsis chromatin-remodeling factor CHR5 regulates plant immune responses and nucleosome occupancy. Plant Cell Physiol. 58, 2202-2216. doi: $10.1093 / \mathrm{pcp} / \mathrm{pcx} 155$

Conflict of Interest Statement: The authors declare that the research was conducted in the absence of any commercial or financial relationships that could be construed as a potential conflict of interest.

Copyright (c) 2018 Meller, Kuźnicki, Arasimowicz-Jelonek, Deckert and FloryszakWieczorek. This is an open-access article distributed under the terms of the Creative Commons Attribution License (CC BY). The use, distribution or reproduction in other forums is permitted, provided the original author(s) and the copyright owner(s) are credited and that the original publication in this journal is cited, in accordance with accepted academic practice. No use, distribution or reproduction is permitted which does not comply with these terms. 